\title{
Calculation of Phenolic O-H Bond Dissociation Enthalpies and Optimization of Docking Scoring Functions
}

\author{
by
}

James Anderson

\author{
A Thesis submitted to \\ the Faculty of Graduate Studies and Research \\ in partial fulfilment of \\ the requirements for the degree of \\ Master of Science \\ in
}

\author{
Chemistry \\ Carleton University \\ Ottawa, Ontario, Canada
}

September 2011

Copyright (C)

2011 - James Anderson 
Library and Archives

Canada

Published Heritage

Branch

395 Wellington Street Ottawa ON K1A ON4 Canada
Bibliothèque et

Archives Canada

Direction du

Patrimoine de l'édition

395 , rue Wellington

Ottawa ON K1A ON4

Canada
Your file Votre référence
ISBN: $978-0-494-83180-9$
Our file Notre référence
ISBN: $978-0-494-83180-9$
NOTICE:

The author has granted a nonexclusive license allowing Library and Archives Canada to reproduce, publish, archive, preserve, conserve, communicate to the public by telecommunication or on the Internet, loan, distribute and sell theses worldwide, for commercial or noncommercial purposes, in microform, paper, electronic and/or any other formats.

The author retains copyright ownership and moral rights in this thesis. Neither the thesis nor substantial extracts from it may be printed or otherwise reproduced without the author's permission.
AVIS:

L'auteur a accordé une licence non exclusive permettant à la Bibliothèque et Archives Canada de reproduire, publier, archiver, sauvegarder, conserver, transmettre au public par télécommunication ou par l'Internet, prêter, distribuer et vendre des thèses partout dans le monde, à des fins commerciales ou autres, sur support microforme, papier, électronique et/ou autres formats.

L'auteur conserve la propriété du droit d'auteur et des droits moraux qui protège cette thèse. $\mathrm{Ni}$ la thèse ni des extraits substantiels de celle-ci ne doivent être imprimés ou autrement reproduits sans son autorisation.
In compliance with the Canadian Privacy Act some supporting forms may have been removed from this thesis.

While these forms may be included in the document page count, their removal does not represent any loss of content from the thesis.
Conformément à la loi canadienne sur la protection de la vie privée, quelques formulaires secondaires ont été enlevés de cette thèse.

Bien que ces formulaires aient inclus dans la pagination, il n'y aura aucun contenu manquant. 


\section{Abstract}

The bond dissociation enthalpy (BDE) of phenol is very sensitive to changes in the substituents added This work will attempt to derive a set of substituent constants for ortho-, meta-, and para-halogenated phenols (F,Cl,Br) using the computational B3LYP functional A multiple linear regression (MLR) was used to derive these constants on exclusively halogenated trainıng sets, resultıng in fits with $\mathrm{R}^{2}>099$ As a test, BDEs were predicted for mixed polyhalogenated phenols, demonstrating the ad-

ditıvity and generality of this approach and resulting in good correlations Accurately predicting the binding affinities for ligands has been a challenge for computational chemists for decades The goal of this work is to develop an energy-based scoring function that will be iteratively optimized to match experimental binding affinities using an MLR fit It was found that after 4-7 iterations the process converged with excellent correlations This method is not prone to overfitting and may be of gencral use in improving docking predictions 


\section{Acknowledgments}

There are many people who have played a significant role in developing me and helping me reach this point. I would like to thank my supervisor, Dr. Jim Wright, for your many wise discussions and your experience that has been a great aid to my own learning. Dr. Hooman Shadnia, who played the role of a friend and mentor when I first joined the lab, proved an invaluable resource for my many questions. I still hum "Here Comes the Weekend" on Friday afternoons. Jamie Davey has spent more time with me over the last two years than any other colleague. Although a fellow student, you are also a role model for the passion you put into every project. When I put on glasses I will always get this strange urge to shout out "It's like I can touch you!".

I would also like to thank my family who has been a great encouragement in my pursuit of knowledge. From the early days before I could walk when my father would discuss chemistry while holding me in his arms to the later years when my mother home schooled my sister and myself all the way through high school, you two have been incredible! Sister, the best sister I have ever grown up with, thank you for your friendship and all the fun we had. I also thank my dear wife and best friend, Shana, for the encouragement you have been while I was working late nights to finish this thesis. You know how to bring out a smile, even when I don't think it's possible

Finally, I owe my greatest thanks to my Heavenly Father who has given me the chance to learn such a fascinating and challenging topic as chemistry and has also given me the love of learning. 


\section{Table of Contents}

Abstract $\quad$ ii

Acknowledgments

Table of Contents iv

List of Tables $\quad$ vii

List of Figures $\quad$ viii

List of Acronyms $\quad x$

1 Introduction 1

1.1 Part I. Substituent Effects .................... 1

1.1 .1 Oxidation ........................ 1

1.1.2 Bond Dissociation Enthalpy ............. 3

1.1 .3 Anti-oxidants . . . . . . . . . . . . . . 4

1.1.4 Substituent Effects on Phenolic BDE $\mathrm{BH}_{\mathrm{H}} \ldots \ldots . . \ldots$

1.1.5 Experimental Value for $\mathrm{BDE}_{O H} \ldots \ldots \ldots . \ldots$

1.1.6 Theoretical Calculation of $\mathrm{BDE}_{\mathrm{OH}} \ldots \ldots . \ldots 9$

1.1 .7 Quantum Mechanics ................. 11

1.2 Part II. Iterative Scoring Functions . . . . . . . . . . . . . . . 13

1.2 .1 Estrogen . . . . . . . . . . . . . . 13 
1.2 .2 Molecular Mechanics . . . . . . . . . . . . . . . . 15

1.2 .3 Bond stretching . . . . . . . . . . . . . 16

1.2 .4 Angle bending . . . . . . . . . . . . . . 17

1.2 .5 Torsion . . . . . . . . . . . . . . . . 17

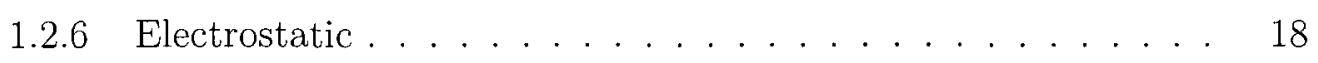

1.2 .7 Van der Waals. . . . . . . . . . . . . . . . 18

1.2 .8 Out-of-plane . . . . . . . . . . . . . . 19

1.2 .9 Stretch-bend . . . . . . . . . . . . . . . . . . 20

1.2 .10 Molecular Docking . . . . . . . . . . . . . . . . . 21

2 Methods $\quad 26$

2.1 Part I. Substituent Effects . . . . . . . . . . . . . . . 26

2.2 Part II. Iterative Scoring Functions . . . . . . . . . . . 28

2.2 .1 Receptor Preparation . . . . . . . . . . . . . . . . . . 29

2.2 .2 Ligand Preparation . . . . . . . . . . . . . . . . . . . 33

2.2 .3 Docking Protocol . . . . . . . . . . . . . . . . . . . 37

3 Results and Discussion $\quad 41$

3.1 Part I. Substituent Effects . . . . . . . . . . . . . . . . . 41

3.1 .1 Training Set . . . . . . . . . . . . . . . 42

3.1 .2 Expanded Set . . . . . . . . . . . . . . . . . . 48

3.1.3 Mixed Polyhalogenated Phenols . . . . . . . . . . . . 48

3.2 Part II. Iterative Scoring Functions $\ldots \ldots \ldots \ldots$

3.2 .1 Validation on Test Set $1 \ldots \ldots \ldots \ldots$

3.2 .2 Validation on Trans A-CD Compounds . . . . . . . . . 59

3.2 .3 Validation Against Overfitting . . . . . . . . . . . . 61 
4 Conclusion $\quad 65$

4.1 Part I. Substituent Effects . . . . . . . . . . . . . . 65

4.2 Part II. Iterative Scoring Functions . . . . . . . . . . . 66

$\begin{array}{ll}\text { List of References } & 68\end{array}$

$\begin{array}{ll}\text { Appendix A } & 73\end{array}$ 


\section{List of Tables}

2 BDE values for $\operatorname{ROS} \ldots \ldots \ldots \ldots \ldots \ldots$

3 Change in BDE Values with Halogen Position . . . . . . . . 8

4 Experimental RBAs for A-CD Compounds . . . . . . . . . . . 35

5 Experimental RBAs for trans- A-CD Compounds . . . . . . . . 36

6 Calculated BDEs for Training Set Phenols . . . . . . . . . . . 43

7 Experimental and Calculated $\triangle \mathrm{BDEs}$ for Halogens $\ldots \ldots \ldots$

8 Parameters for Training and Expanded Sets . . . . . . . . 47

9 Calculated BDEs for Polyhalogenated Phenols . . . . . . . . . . . 49

10 Iteration 1: Docked Poses and Scoring Terms . . . . . . . . . 52

11 Iteration 2: Docked Poses and Scoring Terms . . . . . . . . . 54

12 Iteration 8: Docked Poses and Scoring Terms . . . . . . . . . 56

13 Scoring Terms for Training Set $1 \ldots \ldots \ldots \ldots$

14 Results for Trans A-CD Compounds . . . . . . . . . . . . . . . 59

15 Properties of Additional Training and Test Sets . . . . . . . . . 64 


\section{List of Figures}

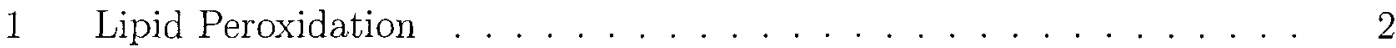

2 Phenoxyl Radical . . . . . . . . . . . . . . . . . . . 4

3 Antioxidant Compounds . . . . . . . . . . . . . . . . . 4

$4 \quad$ ROS Quenching . . . . . . . . . . . . . . . 5

5 Hammett Equilibrium . . . . . . . . . . . . . . . . . 10

6 Estrogen and A-CD structure $\ldots \ldots \ldots \ldots \ldots \ldots$

7 Hydrogen bonding to estradiol . . . . . . . . . . . . . . . 14

8 Molecular Mechanics Terms . . . . . . . . . . . . . . 16

9 Van der Waals Approximation . . . . . . . . . . . . . . . . 18

10 Out-of-plane . . . . . . . . . . . . . . . . 20



12 Iterative SF Optimization $\ldots \ldots \ldots \ldots \ldots \ldots \ldots$

13 Correcting Incomplete Residues . . . . . . . . . . . . . . 30

14 Optimized H-bond Network . . . . . . . . . . . . . . . . . . 31

15 Protein Shells . . . . . . . . . . . . . . . . . . . . . . 32

16 Active Site and Docking Box . . . . . . . . . . . . 33

17 A-CD Structures . . . . . . . . . . . . . . . 34

18 Five Substituent Positions on Phenol . . . . . . . . . . . . . . 42

19 Correlation Between Experimental and Calculated $\triangle \mathrm{BDE}_{O H} \mathrm{~s} \ldots 46$

20 Fit of Predicted vs. Calculated $\triangle \mathrm{BDEs}$ for Polyhalogenated Phenols 50 
21 Iteration 1: Correlation and Docked Pose for E2 . . . . . . . . . 53

22 Iteration 2: Correlation and Docked Pose for E2 . . . . . . . . 55

23 Correlation vs Iteration Test Set 1 . . . . . . . . . . . . 55

24 Iteration 8: Correlation and Docked Pose for E2 . . . . . . . . . 57

25 Correlation for Test Set $1 \ldots \ldots \ldots . \ldots . \ldots 58$

26 Correlation for Trans A-CD . . . . . . . . . . . . . . . . . . 60

27 Correlation of Scrambled vs. Experimental RBAs . . . . . . . . . . 62

28 Correlation vs Iteration Scrambled RBAs . . . . . . . . . . . . . . 62

29 Correlation vs Iteration for Additional Training Sets . . . . . . . . . . 63

30 Flow Chart of Calculations . . . . . . . . . . . . . 73 


\section{List of Acronyms}

\begin{tabular}{ll} 
Acronyms & Definition \\
\hline BDE & Bond Dissociation Enthalpy \\
CPCM & Conductor-like Polarisable Continuum Model \\
DFT & Density Functional Theory \\
DPS & Docked Poses \\
E2 & 17- $\beta$ Estradiol \\
ER $\alpha$ & Estrogen Receptor alpha \\
EDG & Electron-Donating Group \\
EWG & Electron-Withdrawing Group \\
G09 & Gaussian 09 \\
M-Bond & Hydrogen Bond \\
MAF & Mean Absolute Deviation \\
&
\end{tabular}




$\begin{array}{ll}\text { MLM2 } & \text { Medium Level Model } 2 \\ \text { MLR } & \text { Multiple Linear Regression } \\ \text { PDB } & \text { Protein Data Bank } \\ \text { RBA } & \text { Relative Binding Affinity } \\ \text { ROS } & \text { Radical Oxygen Species } \\ \text { SVL } & \text { Scientific Vector Language } \\ \text { SF } & \text { Scoring Function }\end{array}$




\section{Chapter 1}

\section{Introduction}

\subsection{Part I. Substituent Effects}

\subsubsection{Oxidation}

Living organisms are exposed to oxidation every day. Because of this, organisms have developed methods of controlling the presence of these radicals and, thus protecting themselves [1, Wright 1997]. Oxygen containing radicals, known as reactive oxygen species (ROS) are commonly found in the body.

Examples of such molecules are the superoxide radical anion $\left(\bullet^{\bullet} \mathrm{O}_{2}^{-}\right)$, hydrogen peroxide $\left(\mathrm{H}_{2} \mathrm{O}_{2}\right)$, the hydroxyl radical $\left({ }^{\bullet} \mathrm{OH}\right)$, lipid peroxide and lipid peroxyl radicals $\left(\mathrm{ROOH}\right.$ and $\mathrm{ROO}^{\bullet}$ ) and many others [2, Colton and Gilbert 2002, p. 24]. These are present in the body and have various effects. In some cases these can be beneficial to living organisms. Leukocytes are one example; they generate hydrogen peroxide as a mechanism to kill bacteria [3, Klebanoff 1970]. However, in many cases this causes cellular damage which may even lead to cell death. When an ROS is generated in the body it will abstract the nearest accessible hydrogen. This uses up the ROS, but it generates another radical in the molecule that lost the hydrogen $[4$, Halliwell and Gutteridge 1992]. 
One of the molecules that is often attacked by ROS are membrane fatty acids. The allylic hydrogen atoms are easily abstracted, leaving a carbon centered radical. Molecular oxygen reacts readily to form peroxyl radicals which can in turn abstract hydrogen, continuing the cycle (see Figure 1). Thus, ROS can damage the properties of the lipid membrane rather quickly [2, Colton and Gilbert 2002, p. 610].

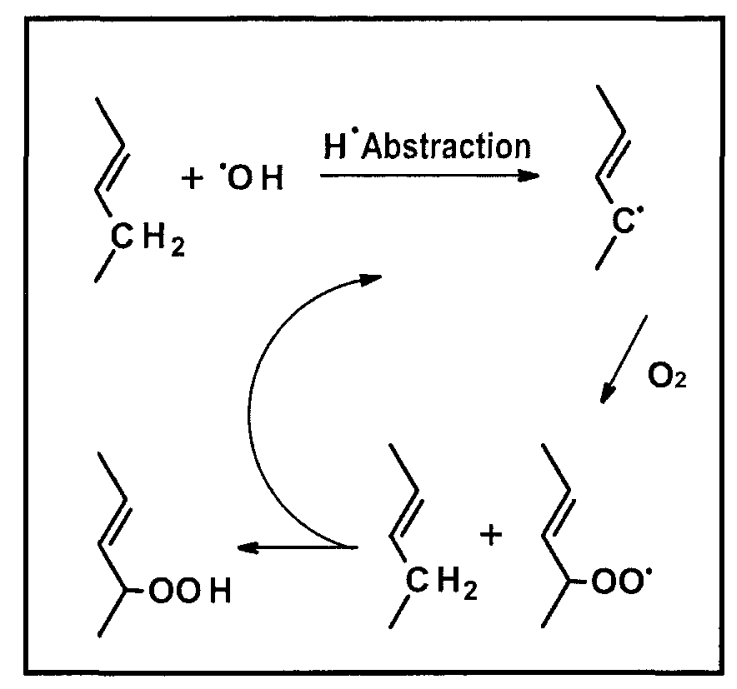

Figure 1: Mechanism of lipid peroxidation.

One method for controlling unwanted oxidation is through the use of low concentrations of antioxidants. These are compounds that quench the radicals without causing damage themselves.

One of the key components found in many natural and commercial antioxidants is the phenol. They make good antioxidants because the phenolic $\mathrm{O}-\mathrm{H}$ bond is relatively weak [5, Klein 2006b] and thus the hydrogen atom is easily abstracted from the phenol by the radical. 


\subsubsection{Bond Dissociation Enthalpy}

A measure of the strength of a bond is the bond dissociation enthalpy (BDE), or the enthalpy change upon breaking the bond. Stronger bonds have larger BDEs and weaker bonds have smaller BDEs. A BDE is calculated by the reaction,

$$
X-Y \rightarrow X^{\bullet}+Y^{\bullet}
$$

where species $\mathrm{X}$ and $\mathrm{Y}$ are bonded together, $\mathrm{X}^{\bullet}$ is a radical species $\mathrm{X}$ and $\mathrm{Y}^{\bullet}$ is the other radical species. The BDE for this prototypical reaction is the sum of the enthalpies of the radicals $\mathrm{X}^{\bullet}$ and $\mathrm{Y}^{\bullet}$ minus the enthalpy of the parent compound $\mathrm{X}-\mathrm{Y}$ or,

$$
B D E_{X-Y}=H_{298, X}^{o} \cdot+H_{298, Y}^{o} \cdot-H_{298, X-Y}^{o}
$$

Specifically, the example that will be examined in detail in this work is the calculation of BDEs for various phenolic compounds. The calculation for phenol is,

$$
B D E_{P h O-H}=H_{298, P h O}^{o}+H_{298, H}^{o}-H_{298, P h O-H}^{o}
$$

Two factors that affect the magnitude of the BDE are the stability of the parent compound and the stabilities of the radical products. Anything that increases the energy gap between the parent and radical increases the BDE. If a substituent stabilizes the parent compound or destabilizes the radical, it increases the BDE. If a substituent is added that stabilizes the radical product or destabilizes the parent compound, then the BDE will be decreased.

Compared with many compounds containing a hydroxyl, the $\mathrm{BDE}_{O H}$ of phenol is remarkably low. For example, the $\mathrm{BDE}_{O H}$ for a saturated alcohol is around 105 $\mathrm{kcal} / \mathrm{mol}$, which is about $20 \mathrm{kcal} / \mathrm{mol}$ higher than that of phenol. The reason phenol has such a low BDE is that the radical is resonance stabilized. That is, the unpaired 
electron is delocalized across the molecule (see Figure 2) lowering the energy [6, Rappoport 2003].

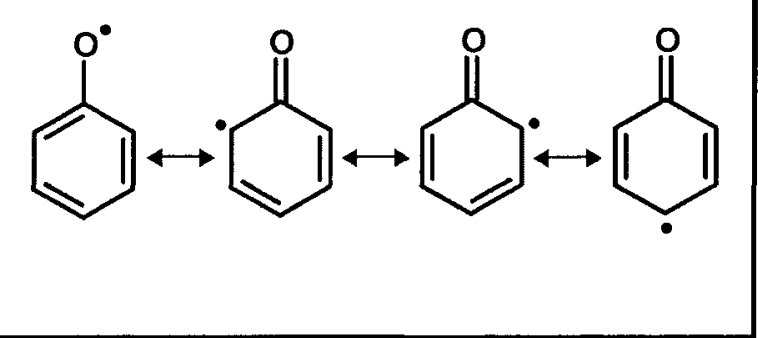

Figure 2: Resonance forms of the phenoxyl radical.

\subsubsection{Anti-oxidants}

There are many sources of oxidants, as even air is full of $\mathrm{O}_{2}$, it follows that there are many compounds used for antioxidant purposes. Several common compounds with antioxidant properties are shown in Figure 3, each of which contains one or more phenolic $\mathrm{O}-\mathrm{H}$ bonds that are the primary place of hydrogen abstraction by ROS.



Figure 3: Common antioxidant compounds featuring phenolic hydroxyls in their backbone. $1 \alpha$-tocopherol, 2 resveratrol, 3 butylated hydroxytoluene 
There are several naturally occurring forms of vitamin E, but the most potent antioxidant form, $\alpha$-tocopherol, is shown in Figure 3. The phenolic hydrogen atom on vitamin $\mathrm{E}$ is donated to the radical species, when acting as an antioxidant $[7$, Burton and Traber 1990]. The second example, resveratrol, is a compound that is naturally occurring in some plants and has been found to have antioxidant properties [8, Fremont 1999]. Thirdly, Butylated hydroxytoluene (BHT) is an antioxidant that is commonly used as an additive [9, Bjorkhem 1991] [10, Branen 1975]. In each case, the antioxidant capability comes from the phenolic hydroxyls.

Another common use for phenolic compounds is as synthetic organic materials [11, Denisov and Khudyakov 1987] and their radicals also have important roles in biological and industrial applications [12, Halliwell and Gutteridge 1989]. Small quantities of antioxidants are added to synthetic polymer products to protect them from oxidation [13, Zhu, Zhang and Fry 1997]. It is important to be able to understand what factors lead to an increase or decrease in the $\mathrm{BDE}_{O H}$, since they have such important roles $[14$, Chandra 2002].

Phenols protect from oxidation by donating their H-atom to the radical (see Figure 4). Although this generates a radical from the antioxidant molecule, they are chosen such that their radical form does not react with the protected molecules.

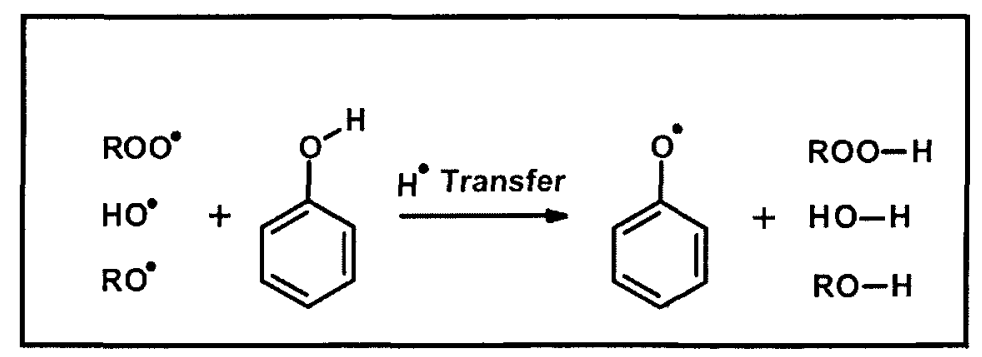

Figure 4: Scheme of phenolic antioxidant donating $\mathrm{H}$-atom to ROS and quenching the radical.

The effectiveness of an antioxidant depends primarily on the strength of the $\mathrm{O}-\mathrm{H}$ 
bond. Although phenols in general have weak $\mathrm{O}-\mathrm{H}$ bonds, there is significant variation depending on the other substituents attached to the phenol. It is important that the phenol have a weak bond (low BDE) because an antioxidant with a phenolic BDE greater than that of the ROS, will not permit $\mathrm{H}$ transfer. For reference, the gas phase BDEs of some ROS products are shown in Table 2, along with the BDE of phenol.

\begin{tabular}{cc}
\hline Molecule & $\mathrm{BDE}_{O H}(\mathrm{kcal} / \mathrm{mol})^{a}$ \\
\hline \hline PhO-H & 87.2 \\
ROO-H $^{b}$ & 89.9 \\
HOO-H & 87.9 \\
RO-H $^{b}$ & 104.9 \\
HO-H & 119.0
\end{tabular}

Table 2: Gas phase BDE values for ROS products and phenol for comparison.

${ }^{a}$ All BDEs obtained from [13, Zhu, Zhang and Fry 1997] except for BDE PhO-H, which was taken from [15, Nix 2006].

${ }^{b} \mathrm{R}$ represents a saturated carbon chain.

The BDE of unsubstituted phenol is roughly the same as those of peroxides and hydroperoxides, but is $20-30 \mathrm{kcal} / \mathrm{mol}$ lower than those of alcohols and water. In this case, phenol would be an effective antioxidant against alkoxyl and hydroxyl radicals, but not work as well for the others. It is of vital importance to know the BDEs of the antioxidant and the target radicals to ensure that the anti-oxidant will be effective.

\subsubsection{Substituent Effects on Phenolic $\mathrm{BDE}_{O H}$}

The ability to raise or lower the $\mathrm{BDE}_{O H}$ of phenol by simply adding or changing substituents has the potential to allow one to design a molecule that has all the desired anti-oxidant properties. Assuming one has found a molecule containing a phenol that has the solubility, metabolic stability or other properties that are desired, the BDE can be 'tuned' to the appropriate range. 
The $\mathrm{BDE}_{O H}$ can be raised by the addition of electron withdrawing groups (EWG) due to a combination of one or both field/inductive effects and resonance effects [16, Zhang et al 2001] As examples, a $\mathrm{p}-\mathrm{NO}_{2}$ rasses the $\mathrm{BDE}_{O H}$ by $6 \mathrm{kcal} / \mathrm{mol}$ through a combination of these effects, whlle $\mathrm{p}-\mathrm{CF}_{3}$ raises the $\mathrm{BDE}_{O H}$ by $4 \mathrm{kcal} / \mathrm{mol}$ using only inductive effects [17, Santes and Simoes 1998] [18, Hansch and Taft 1991]

In contrast, the addition of an electron donating group (EDG) will cause the lowerng of the BDE A group such as p-OMe lowers the BDE by $5 \mathrm{kcal} / \mathrm{mol}$ by resonance effects, even though it has a slight EWG inductive effect Simılarly, p- $\mathrm{NH}_{2}$ also lowers the $\mathrm{BDE}_{O H}$ by $10 \mathrm{kcal} / \mathrm{mol}$ by resonance effects despite the inductive EWG effect [17, Santes and Simoes 1998]

Both resonance and inductive effects contributed to the substituent effect in ortho and para positions, but the meta position is only affected by inductive effects [19, Brown, Okamoto and Ham 1957] As a result, the p-OMe group has a $-5 \mathrm{kcal} / \mathrm{mol}$ effect on the BDE but m-OMe has no effect on the BDE due to the loss of the resonance effects [17, Santes and Simoes 1998] The substituent effects of halogens are of particular interest in this work They are some of the most electronegative elements and thus have a EWG inductive effect However, they are also able to donate electrons from their lone parrs, producing an EDG resonance effect The experimental change in BDE values are contaned in Table 3 [17, Santes and Simoes 1998]

The position of the substituent determines which of the inductive or resonance effects dominates Switching a halogen through ortho, meta and para causes the effect to go from decreasing to increasing and back to decreasing the BDE

There are other methods of lowering the $\mathrm{BDE}_{O H}$ also A set of compounds commonly used as non-staining anti-oxidants in the synthetic polymer industry contain phenols with two t-butyl groups at the ortho positions The t-butyl groups lower the $\mathrm{BDE}_{O H}$ primarily because the steric interactions from the bulky groups raise the 
Substituent

\begin{tabular}{cccc}
\hline Position & Fluorine & Chlorine & Bromine \\
\hline \hline ortho & $-1.9( \pm 2)$ & $-0.7( \pm 1)$ & $-1.7( \pm 2)$ \\
meta & $1.4( \pm 2)$ & $1.2( \pm 1)$ & - \\
para & $-1.0( \pm 1)$ & $-0.2( \pm 1)$ & $0.5( \pm 1)$
\end{tabular}

Table 3: Effect of substituents on gas phase BDE values relative to unsubstituted phenol.

${ }^{a}$ All BDEs obtained from [17, Santes and Simoes 1998].

energy of the parent molecule. An added benefit of the t-butyl groups is that they shield the phenoxyl radical, to some extent, from further reactions [13, Zhu, Zhang and Fry 1997].

\subsubsection{Experimental Value for $\mathrm{BDE}_{O H}$}

Although the nature of the phenolic $\mathrm{OH}$ bond is of great importance, there is still significant variability in the literature over the experimental value of the $\mathrm{BDE}_{\mathrm{OH}}$ of unsubstituted phenol. In 2005, Mulder reported that experimental gas phase $\mathrm{BDE}_{O H}$ values ranged from 85.8 to $91 \mathrm{kcal} / \mathrm{mol}$ [20, Mulder 2005]. One complication to this problem is that many different experiments are used, with some values measured in gas phase while others were measured in liquid phase. Those measured in the liquid phase need to be converted to 'gas-phase' but the assumptions made to correct for hydrogen bonding to the solvent may not be appropriate. The majority of the errors in these 'gas-phase' BDEs were from experiments using highly polar solvents [5, Klein $2006 \mathrm{~b}$. Poor assumptions during conversion or the use of inaccurate auxiliary data can cause the values to be off by several kcal/mol [20, Mulder 2005]. Because of the variations found in the literature, Santos and Simoes published a review in 1998 of approximately 90 literature references to the $\mathrm{O}-\mathrm{H}$ bond in phenol and substituted 
phenols. In this review they predict the most likely gas phase $\mathrm{BDE}_{O H}$ for unsubstituted phenol at $88.7 \pm 0.5 \mathrm{kcal} / \mathrm{mol}$ [14, Chandra 2002]. More recently, however,

a report has been published using new data from a combination of gas-phase and liquid-phase experiments where the experimental gas phase $\mathrm{BDE}_{O H}$ was calculated to be $86.7 \pm 0.7 \mathrm{kcal} / \mathrm{mol}$ [20, Mulder 2005]. They mentioned the value selected by Santos and Simoes, but chose not to comment on the discrepancy. It has been mentioned, however, that Santes and Simoes

"feel that new theoretical and experimental data may invalidate some of their selections because of large discrepancies in the experimental results"

[14, Chandra 2002]. This more recent result by Mulder has been confirmed by several more measurements including one very precise value by Nix et al. where they recorded the gas phase $\mathrm{BDE}_{O H}$ as being $85.8 \pm 0.1 \mathrm{kcal} / \mathrm{mol}$ at $0 \mathrm{~K}$ [15, Nix 2006] which increases to $87.2 \pm 0.1 \mathrm{kcal} / \mathrm{mol}$ at $298 \mathrm{~K}$ [21, Wang and Tang 2010]. This will be used as the reference experimental value in this thesis, as it matches with the average value measured by Mulder and it has higher precision.

\subsubsection{Theoretical Calculation of $\mathrm{BDE}_{O H}$}

One of the advantages of theoretical calculations is the speed and simplicity with which they can be carried out. Theoretical calculations can also be used to examine compounds that are difficult or impossible, to synthesize in a lab. One such example is phenol with an ortho substituent. While it is computationally possible to examine the isomer with the $\mathrm{OH}$ facing toward the substituent separate from the $\mathrm{OH}$ facing away, in an experiment they are not possible to separate [1, Wright 1997].

It has also been suggested that using a set of substituted phenols it would be possible to determine the effect on the $\mathrm{BDE}_{O H}$ for each substituent at each position [1, Wright 1997]. Assuming the initial set of compounds was calculated accurately, this 
might enable BDEs to be predicted without any calculations Instead BDEs could be found by adding these terms together

An idea simılar to this has already been around since 1937, when Hammett introduced his parameters This constant ' $\sigma$ ' represents the electronic effect of replacing the $\mathrm{H}$ in either the meta or para positions of benzene with a different substituent Hammett initially published $14 \sigma$ values that he tabulated and another 17 that were derived from the literature He later extended this set to 44 substituent effects in 1940 [22, Shorter 2000] These values were obtanned from a set of meta- and parasubstituted benzolc acids that were synthesized They were put in solution and the equilibrıum constants were measured for the equilibrıum in Figure 5

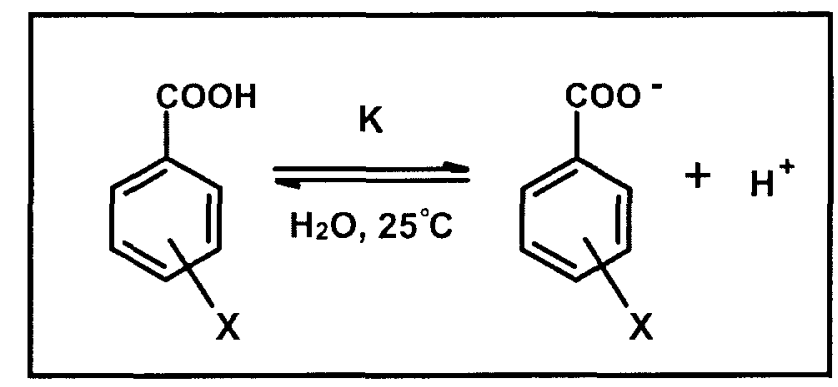

Figure 5: The equllbrium that led to the Hammett parameters

Based on this equilibrium, the $\sigma$ parameter is defined by the equation,

$$
\sigma_{m p}=\log K-\log K_{0}=-p K a+(p K a)_{0}
$$

where $K_{0}$ is the equilibrium constant for benzolc acıd and $K$ is the equilibrium constant for substituted benzene The pKa values are arbitrarly defined in $\mathrm{H}_{2} \mathrm{O}$ at $298 \mathrm{~K}$

It is generally true that side chain reactivity for $m$ - and $p$-substituted benzenes correlate linearly with $\sigma$ Thus, we get the two equations that comprise the Hammett 
equation,

$$
\log k / k_{0}=\sigma \rho
$$

where $\mathrm{k}$ is the rate constant of the side chain reaction, and,

$$
\log K / K_{0}=\sigma \rho
$$

where $\mathrm{K}$ is the side chain equilibrium.

Although these parameters do not measure the strength of the $\mathrm{O}-\mathrm{H}$ bond, it has been observed numerous times in literature that these parameters correlate extremely well with the substituent effects on the $\mathrm{BDE}_{O H}$ of phenol and have been used to calculate predicted $\triangle B D E$ values [23, Brinck et al 1997] [24, dos Santos et al 2008].

\subsubsection{Quantum Mechanics}

When talking about quantum mechanics it is always good to start at the beginning, the Schrodinger equation, which can be written as,

$$
\left\{-\frac{\hbar^{2}}{2 m} \nabla^{2}+V\right\} \Psi(x, y, z)=E \Psi(x, y, z)
$$

Where $\nabla^{2}=\frac{\delta^{2}}{\delta x^{2}}+\frac{\delta^{2}}{\delta y^{2}}+\frac{\delta^{2}}{\delta z^{2}}$. This is often shortened by defining the Hamiltonian operator, $\mathrm{H}=-\frac{\hbar^{2}}{2 m} \nabla^{2}+V$. This gives us,

$$
H \Psi=E \Psi
$$

However, except for special cases this equation can only be solved exactly for systems containing only one electron. A method that produces an approximation to the Schrodinger equation is the Hartree-Fock approximation. This assumes that the Born-Oppenheimer approximation is true, or that the nuclei are fixed relative to the electrons. This allows the wavefunction to be split into the nuclear component and 
the electronic component. This allows us to solve the Schrodinger equation for the electrons alone. The other assumption in Hartree-Fock is that the wavefunction can be described as a Slater determinant. [25, Molecular Modeling 2001]

The most popular strategy for the solution to the Hartree-Fock equations is to write each spin orbital as a linear combination of single electron orbitals which are usually called basis functions. The ideal choice for approximating an atomic orbital (basis function) would be a Slater type orbital; however since Slater functions are computationally expensive, Gaussian functions are typically used. Thus, HartreeFock attempts to solve the electronic structure of atoms by creating a wavefunction with each electron. [25, Molecular Modeling 2001]

Another method used to determine the electronic structures of atoms is known as density functional theory (DFT). The main assumption in DFT is that the total electronic energy is related to the overall electronic density. DFT tries to calculate the overall electronic density and thus, the total electronic energy. This has the benefit of reducing the problem from considering an electron density that relies on the coordinates of each electron ( $\mathrm{N}$ electrons with $3 \mathrm{~N}$ coordinates) down to the coordinates of the overall electronic density ( $N$ electrons with 3 coordinates). [25, Molecular Modeling 2001]

The functional used in this work is known as the B3LYP functional. It is a hybrid Hartree-Fock/DFT method which incorporates the gradient correction to the exchange functional by Becke and the Lee-Yang-Parr correlation functional with the local spin density approximation exchange result with the form,

$$
E_{\chi C}=\left(1+a_{0}\right) E_{\chi}^{L S D A}+a_{0} E_{\chi}^{e x a c t}+a_{\chi} \Delta E_{\chi}^{B 88}+a_{c} \Delta E_{c}^{P W 91}
$$

Where $\mathrm{a}_{0}=0.2, \mathrm{a} \chi,=0.72$, and $\mathrm{a}_{c},=0.81$ as parameterized using the $\mathrm{G} 2$ molecule 
data set, $E_{\chi}^{\text {exact }}$ is the exact exchange energy, $\Delta E_{\chi}^{B 88}$ is Becke's 1988 gradient correction, $\Delta E_{c}^{P W 91}$ is the 1991 gradient correction for correlation of Perdew and Wang and $\mathrm{E}_{\chi}^{L S D A}$ is the electron-gas parameterization that Becke took from work published in 1992 by Perdew and Wang. [25, Molecular Modeling 2001] [26, Becke 1993] [27, Lee $1988]$

\subsection{Part II. Iterative Scoring Functions}

\subsubsection{Estrogen}

The estrogen receptor is very important. There are two subtypes, ER $\alpha$ and ER $\beta$, which have been the focus of much research in an attempt to develop drugs with beneficial effects on these receptors [28, Dahlman-Wright et al 2006]. These may be

used to treat symptoms or diseases such as hot flashes and osteoporosis as well as having the potential of being used in the treatment for breast cancer [29, MacGregor and Jordan 1998].

The natural ligand that binds into the estrogen receptors is the steroid estradiol (E2) and is shown in Figure 6. Upon binding, the receptor changes conformation such that it can dimerize with another ligand bound estrogen receptor. A number of other factors bind to the protein dimer and the whole complex moves to the nucleus, where DNA transcription can begin [28, Dahlman-Wright et al. 2006]. The goal of much effort in drug design is to find a synthetic compound that will bind in the same manner, causing the same effects, as the natural ligand so that this process can be jump started when required.

A series of synthetic estrogens were developed previously [30, Wright et al 2011] [31, Asim et al 2009] that have varying activity on the receptors. They have been called 'A-CD' compounds, since they share the same $\mathrm{ABCD}$ ring backbone as $\mathrm{E} 2$ 

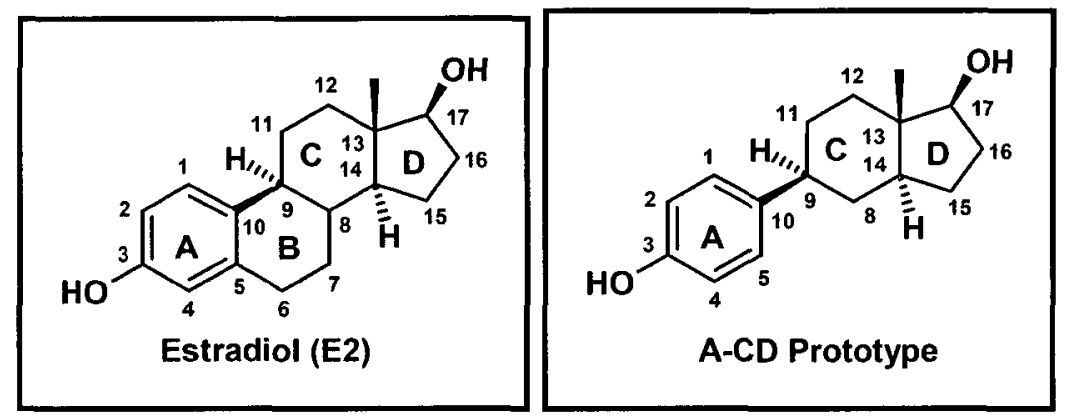

Figure 6: Estradiol the native estrogen ligand (left) and the synthetic A-CD estrogen prototype (right).

except in the fact that the B-ring is missing, shown in Figure 6. For ease of comparison the standard steroid carbon numbering is retained.

The key to binding and activating the estrogen receptors is found in two H-bonding groups at either end of the binding pocket. The $\mathrm{C} 3-\mathrm{OH}$ forms an $\mathrm{H}$-bond network at one end while the $\mathrm{C} 17-\mathrm{OH}$ binds to the other side. The key residues around the $\mathrm{C} 3$ $\mathrm{OH}$ are Glu353, Arg394 and HOH2009 with His524 at the other side (Figure 7).


Figure 7: Hydrogen bonding network for estradiol bound to ER $\alpha$ as optimized from the crystal structure $1 \mathrm{GWR}$. The H-bonding network surrounding the $3-\mathrm{OH}$ (left) and the H-bond at the 17-OH end (right).

A compound will generally bind well to the ER receptors if it contains the ability to maintain these H-bonding networks. This part of the work will use computational means, such as potential energy calculations and molecular docking to analyze the interactions of the $\mathrm{A}-\mathrm{CD}$ estrogens in an attempt to predict their binding affinities 
accurately.

\subsubsection{Molecular Mechanics}

Calculation of electronic configurations using quantum mechanics for small molecules is relatively easy. However, as the number of atoms in the system increases, the number of electrons does so even more quickly. When dealing with large molecules such as proteins, the computational time required to run calculations becomes unfeasible, even when only a few electrons per atom are considered. In order to keep calculations on a reasonable timescale, certain approximations must be made. Molecular mechanIcs ignores electrons and computes molecular structures and properties by treating atoms as balls held together by springs representing bonds. The atoms are given charges and radii while bonds have an equilibrium length and stretch/compression penalties The potential energy of a particular conformation of the system is given as a sum of the bonded and the non-bonded terms, with each molecular mechanical force-field having slight variations on exactly how these terms are calculated The force-field used in this work is known as MMFF94s, which was developed by Merck [32, Halgren 1996 $]^{1}$. The non-bonded terms calculated in this force-field are electrostatic, or charged, and van der Waals, or hydrophobic, while the bonded terms are bond stretch, bond angle bend and dihedral (or torsion), with two other terms, stretch-bend and out-of-plane that are used to parameterize specific aspects of this force-field. The five key terms are shown in Figure 8.

\footnotetext{
${ }^{1}$ The parameters for MMFF94 can be found at $\mathrm{ftp} / / \mathrm{ftp}$ wiley com/public/journals/Jcc/suppmat/17/490 and the modifications to out-of-plane and torsion parameters can be found at ftp //ftp wley com/public/journals/jcc/suppmat/20/720/
} 


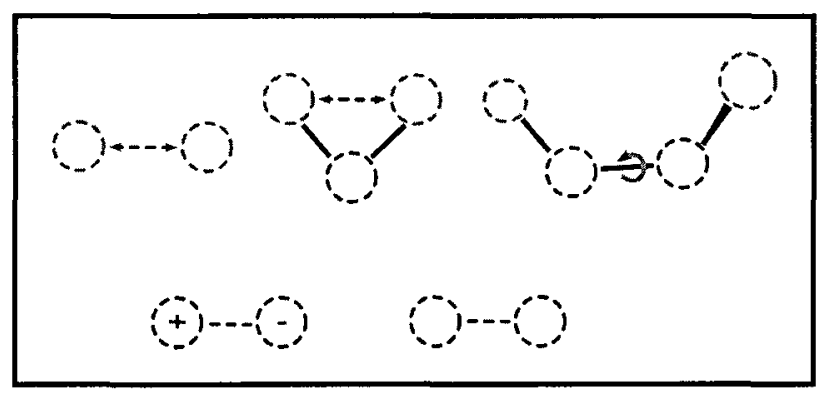

Figure 8: The five key terms that make up a molecular mechanics force-field: (from top left to bottom right) bond stretching, angle bending, torsion, electrostatics and van der Waals.

\subsubsection{Bond stretching}

A bond between two atoms has an ideal, or equilibrium, length where it is at its lowest energy. Either stretching or compressing this bond from that distance will increase the energy by a certain amount. The specific features of the bond depend on the properties of atoms that form the bond. In general, Hooke's law is the equation that is used to describe the variance of energy over bond length which has the form,

$$
E_{\text {stretch }}=\frac{k}{2}\left(r_{x}-r_{e}\right)^{2}
$$

$\mathrm{k}$ is the stretch constant of the bond, $\mathrm{r}_{e}$ is the equilibrium length of the bond and $r_{x}$ is the bond length after stretching or compressing. While the Hooke's law is reasonable for bond lengths near equilibrium, it behaves poorly as the bond is further from equilibrium. A more sophisticated way to deal with the bond stretching term involves the expansion of the Morse potential using Taylor series. The MMFF94s force-field truncates it to the quartic term, as shown below,

$$
E_{\text {stretch }}=K_{\text {stretch }}\left(r_{x}-r_{e}\right)^{2}\left[1+c s\left(r_{x}-r_{e}\right)+7 / 12\left(\operatorname{cs}^{2}\left(r_{x}-r_{e}\right)^{2}\right)\right]
$$

where, cs is the cubic-stretch constant. 


\subsubsection{Angle bending}

When three or more atoms are involved in a molecule the potential for angle bending occurs. The bending of an angle is also commonly described using Hooke's law,

$$
E_{\text {angle }}=\frac{k}{2}\left(\theta_{x}-\theta_{e}\right)^{2}
$$

where, $\mathrm{k}$ is the angle bending constant, $\theta_{x}$ is the distorted angle and $\theta_{e}$ is the equilibrium angle. This can again be expanded by including higher order terms (MMFF94s only includes one more),

$$
E_{\text {angle }}=K_{0}\left(\theta_{x}-\theta_{e}\right)^{2}\left[1+c b\left(\theta_{x}-\theta_{e}\right)\right]
$$

where, $\mathrm{K}$ is again the force constant, $\theta$ is the angle between three atoms bonded together and $\mathrm{cb}$ is the cubic-bend constant. However, when the angle is linear or almost linear, the angle term changes to,

$$
E_{\text {angle,linear }}=K_{\text {lınear }}(1+\cos \theta)
$$

\subsubsection{Torsion}

A torsional angle is made between four consecutively bonded atoms i, j, $\mathrm{k}$ and $\mathrm{l}$. The angle is defined as the angle between the plane made by atoms $\mathrm{i}, \mathrm{j}$ and $\mathrm{k}$ and the plane made by atoms $\mathrm{j}, \mathrm{k}$ and $\mathrm{l}$. As the torsional angle increases beyond the optimum value, the energy increases. The energy term is calculated as follows,

$$
E_{\text {torsion }}=0.5\left[V_{1}(1+\cos \theta)+V_{2}(1+\cos 2 \theta)+V_{3}(1+\cos 3 \theta)\right]
$$

where $V_{1}, V_{2}$ and $V_{3}$ are force constants that relate to the atoms involved in the dihedral. 


\subsubsection{Electrostatic}

The first of the non-bonded terms, the electrostatic term accounts for the interactions between charges over space. It is calculated using a buffered coulombic form,

$$
E_{\text {electrostatıc }}=\left(q_{\imath} q_{\jmath}\right) /\left(D\left(r_{\imath \jmath}+\delta\right)\right)
$$

where $q_{\imath}$ and $q_{3}$ are the partial charges of the atoms $\mathrm{i}$ and $\mathrm{j}, \mathrm{D}$ is the dielectric constant, $r_{\imath \jmath}$ is the distance between atoms $i$ and $j$ and $\delta$ is a buffering constant that is equal to $0.05 \AA$.

\subsubsection{Van der Waals}

The van der Waals energy term describes the interactions that cannot be described by electrostatic interactions. Unlike electrostatic interactions, where the term is either attractive or repulsive, van der Waals interactions have both attractive and repulsive terms (see Figure 9).

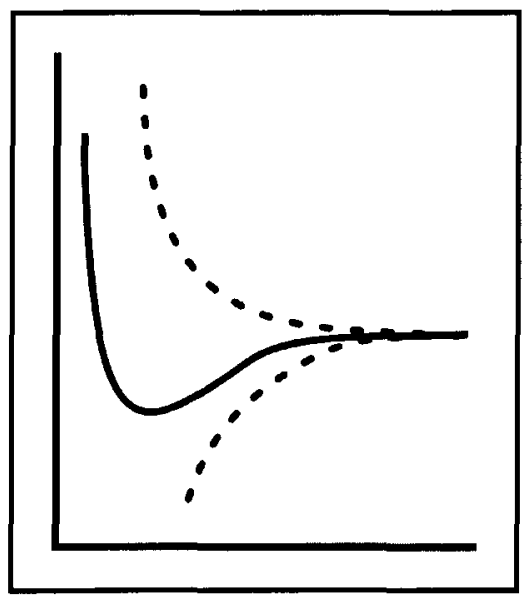

Figure 9: The attractive (lower dashed curve) and repulsive (upper dashed curve) terms sum together to form the picture.

At larger distances the attractive forces dominate and as the distance decreases the 
repulsıve force become more prominent. Dispersive, or instantaneous induced dipole, forces are the source of the attractive component Repulsions between electrons begin as the atoms are brought closer together Electrons with the same quantum numbers are not permitted in the same system, and so the electron density shifts away from the internuclear area and we see repulsions between the two nuclei One of the most commonly used functions that models these interactions is the Lennard-Jones function,

$$
E_{L-J}=k \in\left[\left(\frac{\sigma}{r}\right)^{n}-\left(\frac{\sigma}{r}\right)^{m}\right], \quad k=\left[\frac{n}{(n-m)}\right]\left(\frac{n}{m}\right)^{\frac{m}{(n-m)}}
$$

where $\epsilon$ is the well depth, $\sigma$ is the collision drameter, $\mathrm{n}$ is the exponent for the repulsive term and $m$ is the exponent for the attractive term. Typical values for $n$ and $m$ that are commonly used are 12 and 6 The MMFF94s force-field uses a variant of this form labcled a 'buffered 14-7' potential

$$
E_{v d W}=\epsilon\left(\frac{1+\delta}{\rho+\delta}\right)^{(n-m)}\left(\frac{1+\gamma}{\rho+\gamma}-2\right)
$$

where $\rho=\mathrm{r} / \mathrm{r}^{\bullet}, \mathrm{r}^{\bullet}$ is the distance where the energy reaches a minimum and both $\delta$ and $\gamma$ are constants applying to all interactions between the atoms For the 'buffered 14-7' potential, the terms are chosen as $\mathrm{n}=14, \mathrm{~m}=7, \delta=0.07$ and $\gamma=0$ 12. The equation then becomes,

$$
E_{v d W}=\epsilon\left(\frac{1.07 r^{\bullet}}{r+0.07 r^{\bullet}}\right)^{7}\left(\frac{112 r^{7}}{r_{7}+012 r^{7}}-2\right)
$$

\subsubsection{Out-of-plane}

The two other terms in the MMFF94s force-ficld are not present in every force-field The first is the out-of-plane term and is used to keep atoms in plane that would otherwise be out of the plane. For example, the oxygen on cyclobutanone as in Figure 10, 


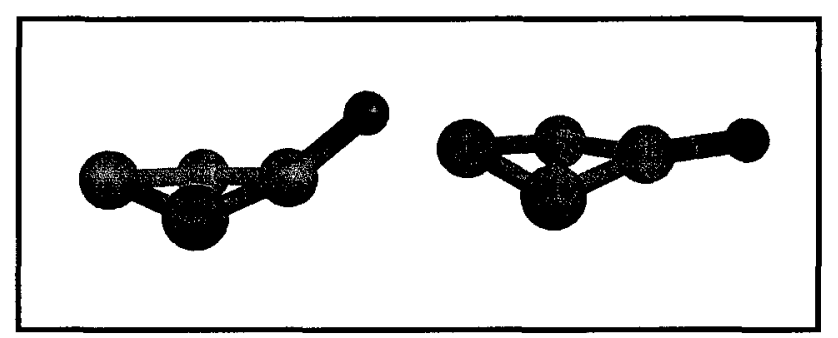

Figure 10: Cyclobutanone with hydrogens omitted for clarity showing $\mathrm{C}=\mathrm{O}$ nonplanar (left) and planar(right).

would be modeled with the $\mathrm{C}=\mathrm{O}$ out of the plane of the ring using the stretch and angle terms. Since force-fields do not calculate electronic properties, they do not account for the $\pi$-bonding energy, which is optimized when planar. Thus a term is added that forces the oxygen back into plane with the ring. The oop term used in MMFF94s is,

$$
E_{\text {oop }}=K_{\text {oop }}\left(\chi_{\imath \jmath k, l}\right)^{2}
$$

where $\mathrm{K}$ is the force constant, $\chi$ is the Wilson wag angle between bond $\mathrm{jl}$ and plane ijk.

\subsubsection{Stretch-bend}

The last term in the MMFF94s force-field, stretch-bend, is a cross term. Cross terms happen when the effect of one action causes another. There are cross terms between each type of motion, ie. stretch-stretch, stretch-torsion, bend-bend, bend-torsion and stretch-bend. However, stretch-bend is only one that is modeled in MMFF94s. One example of this type of motion would occur when an angle between two atoms was decreased and the atom bonds concurrently lengthened to reduce the interaction between the atoms. Below is the equation used to describe the energetic of this motion, 


$$
E_{s-b}=\left[K_{\imath \jmath k}\left(r_{\imath \jmath}-r_{\imath \jmath}^{0}\right)+K_{k \jmath \imath}\left(r_{k \jmath}-r_{k \jmath}^{0}\right)\right]\left(\theta-\theta^{0}\right)
$$

where $K_{\imath \jmath k}$ and $K_{k \jmath \imath}$ are the force constants that couple the stretching of the $\mathrm{ij}$ and $\mathrm{kj}$ bonds to the ijk angle.

All these terms are summed together to calculate the total energy of the molecular mechanics system. The simplicity of these equations makes it possible to calculate the energy of large molecules, such as proteins.

\subsubsection{Molecular Docking}

The goal of molecular docking is to predict and analyze the combined interactions of multiple molecules when complexed together. The most common use for docking is currently to predict the binding poses of compounds in protein targets. One of the earliest examples of a docking program was the program published by Kuntz and coworkers [33, Kuntz et al 1982], called DOCK. The average docking can be performed relatively quickly compared with the process of synthesizing and testing a compound experimentally. Thus, it is much more economical to perform tests in siluco first, and then only test the compounds that are predicted to be promising. Although there has been vast improvement in this field since the start, it still requires significant improvements before achieving highly accurate docking [34, Moitessier et al. 2008].

The general procedure of docking involves a target, usually a protein, and a set of candidate compounds to be tested for binding to that target. The computational method optimizes the placement of each compound in the target, analyzes the best placement for each compound and returns a ranking of the compounds (Figure 11).

Currently, docking is primarily used to identify important binding modes, enrich a compound pool, and analyzing key drug interactions. Although docking can usually find important binding modes, accurately predicting binding affinities has had much 


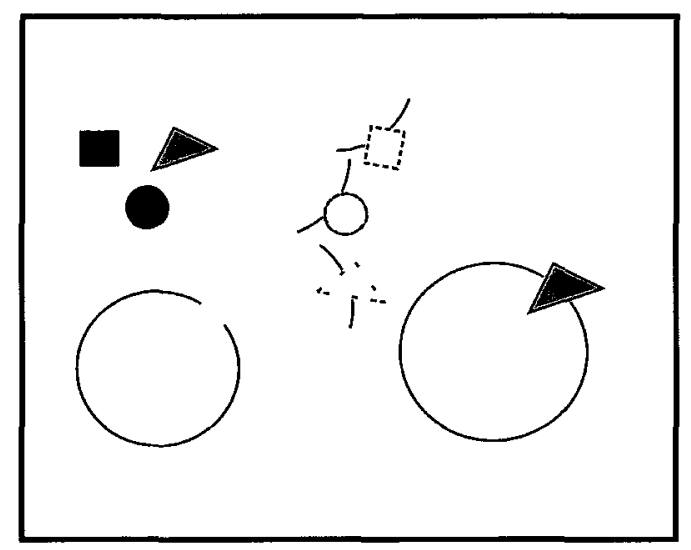

Figure 11: Overview of docking Starting with target and set of compounds (left), determining best fit for cach compound (middle) and final best pose for top compound (right)

worse success [35, Warren 2006] Some of the challenges that must be faced when performing a docking calculation include the high computatıonal demands required to calculate the interactions between the many atoms, dealing with many ligand conformations, accounting for protem flexibility and conformational changes as well as interactions with other factors Docking protocols have many different ways of dealing with each of these challenges

In an attempt to find the balance between computational demands and accuracy, different force-fields have been developed that merge hydrogens to their respective carbons [36, Jorgensen and Tirado-Rives 1988] At the other end of the spectrum, some force-fields include more than the standard number of terms, such as MMFF94s, and some programs have integrated molecular mechanıcs and quantum mechanical calculations as in Gaussian's ONIOM [37, Dapprich et al 1999] [38, Rahu and Merz $2005]$

The conformation of a ligand may change depending on the features of the system that surrounds it If prior knowledge of the preferred conformation is not known, then one way to determme the best ligand conformation is to try all possibilities 
and see which one is ranked highest. Different docking programs attempt to find the optimum balance in computation versus accuracy by using more or less rigorous ligand conformation searching methods [39, Merz 2010].

Modeling protein flexibility has been a challenge for many docking programs. One possibility is to dock into multiple conformations of the same protein [34, Moitessier et al 2008], while another variation is the ensemble docking algorithm used by Huang and Zou where multiple structures are used and the optimum is selected [40, Huang and Zou 2006] [41, Stjernschantz and Oostenbrink 2010].

One of the largest areas in computational drug design is the development of scoring functions (SFs) to rank-order a set of docked poses. They are generally classified into three categories in the literature: empirical, knowledge based and force-field based.

In empirical SFs, the energy of binding is calculated from many smaller components, such as number of H-bonds, molecular weight, surface area or number of rotatable bonds. Each term is assigned a scaling factor that is optimized by regression to match observed binding affinities (Equation 22) [34, Moitessier et al 2008].

$$
\Delta G_{b i n d}=\Delta G_{0}+\Delta G_{H-b o n d}(\# H-\text { bonds })+\Delta G_{M W}(M W)+\Delta G_{S A}(S A)+\Delta G_{R o t}(\# R o t)
$$

One downside to these methods is the requirement for a training set of experimental binding affinities.

Knowledge based SFs do not require binding affinity data as they are built by extracting structural information from sets of crystal structures of ligand-protein complexes. The interactions of the ligand with the protein are grouped into atomtype pairs and statistical analysis is performed on the distribution of these pairs to convert this into potentials. Thus, pair interactions that do not occur frequently are given lower significance than those that appear more frequently [42, Velec 2005] [34, Moitessier et al 2008]. 
Finally, force-field based SFs are designed to reproduce the energy of ligand binding by the summing various force-field energy terms. These terms often require scaling factors to be applied to achieve predictiveness [34, Moitessier et al 2008] [43, Hecht 2009].

One of the main goals of developing scoring methods is to perform virtual screening of large compound databases. The massive number of compounds that are searched in such a screening requires that the time spent analyzing each compound be kept at a minimum. This work will assume that the compound database has already been refined and that we are working with a few ligands selected for lead optimization. Since we will be working with ligand sets that contain $<100$ ligands, we have the ability to examine them in greater depth than is possible with virtual screening.

The procedure that is examined here involves the iterative optimization of a scoring function aimed at accurately predicting relative binding affinities [30, Wright 2011]. The SF uses force-field terms and a solvation energy term, combining them to match with observed binding affinities using a multiple linear regression (MLR) analysis. This function is iteratively optimized by reselecting top poses based on the old SF and calculating the SF again based on this new set of poses. Creation of the set of DPs is the most computationally demanding step and only needs to be performed once. Sorting and iterating through the DPs to optimize the SF requires much less time.

A general overview of the steps involved in the process of iterative scoring function optimization is shown in Figure 12. 


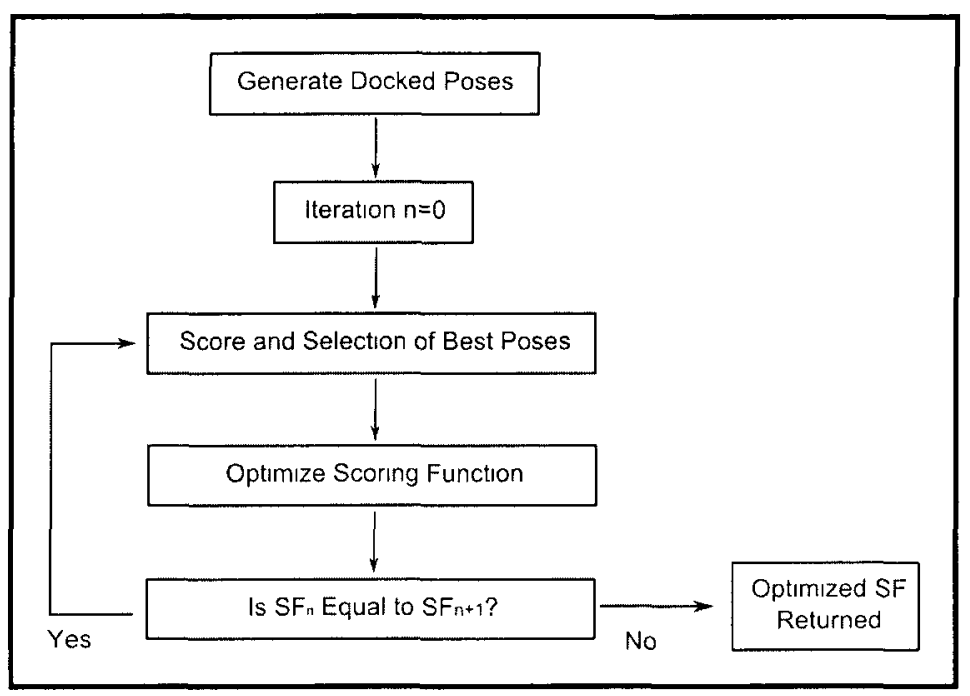

Figure 12: The steps involved in an iterative optimization of a SF, note that the computationally intensive step, generation of DPs only occurs once.

This kind of iterative pose selection has been highlighted previously in the literature, often with reference to the dangers of overfitting. In one example, Huang and Zhou used an iterative procedure to derive interaction potentials for ligand-protein interactions using a knowledge based procedure [44, Huang and Zou 2006a]. Another example is the empirical scoring function that Martin and Sullivan [45, Martin and Sullivan 2008] describe called 'AutoShim' where the SF uses an iterative procedure to select poses. As will be shown in the following pages, the procedure for iterative pose selection employed here is simple and predictive as well as avoiding the danger of overfitting. 


\section{Chapter 2}

\section{Methods}

Calculations run on Gaussian 09/03 were submitted to the High Performance Computing Virtual Laboratory (HPCVL), a cluster of powerful Sun computers located across several universities and colleges in Ontarıo Calculations run in the Molecular Operating Environment 2009 were performed on a local cluster of AMD dual core processors running Window XP professional SP3 For an overview of the programs used in this work, see Appendix 1.

\subsection{Part I. Substituent Effects}

The program Gaussian [46, G09] was used for all DFT calculations involving substituent effects The Molecular Operating Environment (MOE) [47, MOE2009] was used to generate three dimensional atom coordinates for the compounds and create input files to be run in Gaussian.

The compounds were generated in MOE and then saved into a MOE database A script written in MOE's Scientıfic Vector Language (SVL) written by H Shadnı was used to extract the atom coordinates and insert them into a template Gaussian input file with the desired runtıme parameters These Gaussian input files were then submitted to the HPCVL cluster and processed. 
Calculation of gas phase phenolic O-H BDEs were carried out according to the MLM2 method [48, DiLabio et al. 1999], which is defined as follows. The geometry of the structures was first optimized using the OPT command in Gaussian with the B3LYP hybrid functional [49, G09 User Reference] [26, Becke 1993] [27, Lee 1988] and the $6-31 G(d)$ basis set. Using the optimized coordinates, vibrational frequencies were also calculated at the same level using the FREQ=ReadIsotope command. This allows the calculations to be performed at alternate temperatures, pressures, frequency scale factors or isotopes. The default values for temperature $(298.15 \mathrm{~K})$, pressure (1.0 atm) and isotope were chosen, however, the frequency scale factor was set to 0.9806 . This value was found to be appropriate previously [48, DiLabio et al 1999]. The vibrational analysis provided the thermal correction for enthalpy values for both the phenol $(\mathrm{ArOH})$ and the radical $\left(\mathrm{ArO}^{\bullet}\right)$. Electronic energies of the compounds were calculated using the UB3LYP functional and the larger $6-311+\mathrm{G}(2 \mathrm{~d}, 2 \mathrm{p})$ basis set for the phenols and the ROB3LYP $/ 6-311+G(2 d, 2 p)$ level for radicals. Summing the thermal correction for enthalpy with the electronic energy provided the enthalpy for the compound. The enthalpy of $\mathrm{H}^{\bullet}$ was calculated by setting the electronic energy to its exact value of -0.50000 a.u. This was done to achieve BDEs in good agreement with experiment [50, Johnson et al 2003].

The $\mathrm{BDE}_{O H}$ for the formation of the phenoxyl radical was calculated by:

$$
B D E_{O H}=\Delta H_{298, r x n}^{o}=H_{298, A r O}^{o}+H_{298, H^{\bullet}}^{o}-H_{298, A r O H}^{o}
$$

$\mathrm{BDE}_{O H}$ values were calculated for each compound in the same manner. Changing method/basis set can result in large variances in $\mathrm{BDE}_{O H}$ values, however, the relative difference between $\mathrm{BDE}_{\mathrm{OH}}$ values remains constant [14, Chandra 2002]. Thus, BDE 
differences ( $\triangle \mathrm{BDEs}$ ) were calculated as follows

$$
\triangle B D E=B D E_{X-p h e n o l}-B D E_{\text {phenol }}
$$

A positive value of $\triangle B D E$ designates a stronger substituted phenolic $\mathrm{OH}$ bond and a negative value designates a weaker $\mathrm{OH}$ bond

Once calculated, the $\triangle \mathrm{BDEs}$ were correlated to the number and type of substituents by performing a multiple linear regression (MLR) with $\triangle B D E$ as the dependent variable and the independent variables being the type $(\mathrm{F}, \mathrm{Cl}$ or $\mathrm{Br})$ and position (ortho $o_{\text {toward }}$, ortho $o_{\text {away }}$, meta and para) A set of Hammett-like coefficients were returned from the MLR that could be used to calculate the predicted $\triangle \mathrm{BDE}$ for an arbitrarly substituted phenol as follows

$$
\triangle B D E_{(p r e d)}=C_{X H-b o n d}(\# H-\text { bond } X)+C_{X o}(\# o-X)+C_{X m}(\# m-X)+C_{X p}(\# p-X)
$$

where the terms are the number of internal $\mathrm{H}$-bonds between $\mathrm{OH}$ and the halogen substituent, the number of halogen substituents at each position (ortho, meta and para), $\mathrm{X}$ represents any of $\mathrm{F}, \mathrm{Cl}$ or $\mathrm{Br}$ and the coefficients $(\mathrm{C})$ are the parameters returned by the MLR

\subsection{Part II. Iterative Scoring Functions}

MOE 2009 was used extensively for structure preparation, potential energy minımizations, dockıng calculations, energy reading and final pose analysis All docking calculations and energy minimizations used the MMFF94s force field in the gas phase [32, Halgren 1996], as implemented in the MOE software, unless otherwise mentioned This force field was developed for energy minımizations and was parameterızed to treat both proteins and small molecules well, making it useful in medicinal chemistry [51, Halgren 1999] A distance-dependent dielectric constant of 1 was used 
with a cutoff at $10 \AA$.

\subsubsection{Receptor Preparation}

Three dimensional coordinates, in the form of X-ray crystallographic data, were obtained for human recombinant $\mathrm{ER} \alpha$ from the Protein DataBank [52, RCSB]. The file with PDB ID: 1GWR was chosen as it contained the native E2 ligand bound in a ligand binding domain (LBD) homo dimer. The dimer is in complex with coactivator peptides, has a good resolution of $2.4 \AA$ and also contains the associated water molecules [53, Warnwark 2002]. For the purposes of this docking study, only one of the two monomers, chain B, was kept, along with its bound ligand and water molecules.

Heavy atom coordinates are contained in the PDB file, but the hydrogen atoms are missing. The hydrogen atoms must be included before energy minimizations can be performed. The program MOE has the option to add hydrogens by default, which assigned charged residues according to $\mathrm{pH} \mathrm{7,} \mathrm{giving} \mathrm{the} \mathrm{standard} \mathrm{geometry} \mathrm{for} \mathrm{each}$ atom type contained in the PDB file. In reality, many hydrogen atoms do not have completely standard geometry. Thus, the resulting file was high in energy, as many hydrogens were placed in orientations that clashed with other atoms. These clashes were dealt with later by energy minimization using the default minimization scheme in MOE. This scheme uses a combination of three methods: steepest descent, conjugate gradient and truncated Newton. Energy minimizations begin with steepest descent until the gradient of the system reaches $1000 \mathrm{kcal} / \mathrm{mol} \AA$ then conjugate gradient takes over. The minimization continues with conjugate gradient until the gradient reaches $100 \mathrm{kcal} / \mathrm{mol} \AA$, at which point truncated Newton is used until the system is fully minimized.

The crystal structure provides vital information on the orientation of atoms and residues that provides the basis for further analysis and interpretation of the protein. However, some parts of the structure are incomplete and must be corrected. This 
often happens towards the outside of the protein, where there is more flexibility in the amino acid residues. One example of such an incomplete residue is Lys531 (Figure 13) which is missing the $\epsilon$-carbon and the amino at the end of the side chain.

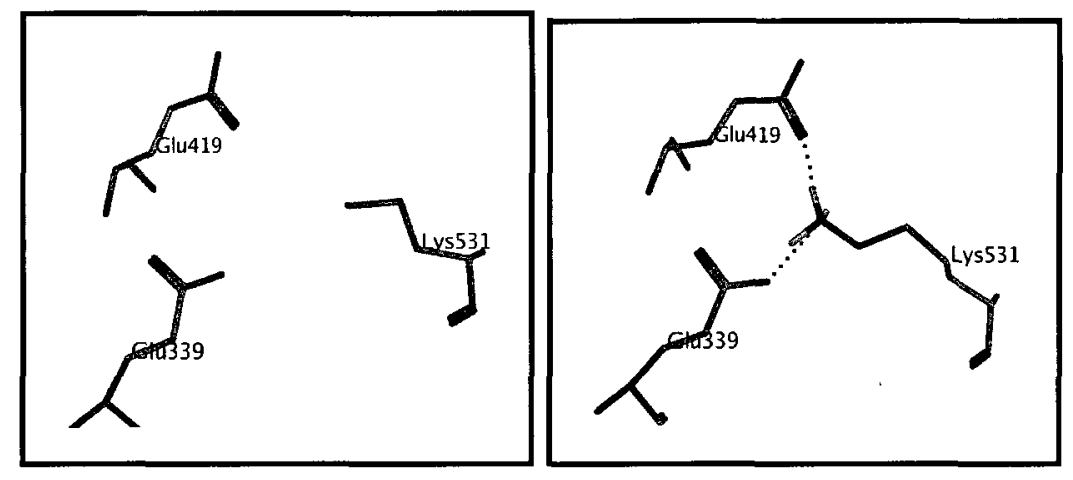

Figure 13: Incomplete Lys531 residue as found in the 1GWR monomer B crystal structure (left). Fixed Lys531 residue with complete side chain and restored hydrogen bond interactions with Glu339 and Glu419 (right).

In this example it is clear the optimal orientation of the side chain is facing the nearby charged Glu residues enabling them to participate in a H-bonding network with Lys. The full residue was added in using a function in MOE called the Rotamer Explorer that generates a list of possible mutations ranked by its own scoring function. Each rotamer was compared with the side chain atoms available in the crystal structure. The highest ranked rotamer that matched with the crystal structure was chosen and the side chain was allowed to relax through a coarse energy minimization. The restored H-bond network can also be seen in Figure 13.

Another area of the protein that requires particular care is the orientation of the hydrogens in the active site. There are several key residues, Arg394, Glu353, His524 and $\mathrm{HOH} 2009$ that participate in binding $\mathrm{E} 2$ within the active site. The $\mathrm{OH}$ on $\mathrm{C} 3$ of E2 forms an important H-bonded bridge with Arg394, Glu353 and HOH2009 [54, Prathipati 2006]. At the other end of $\mathrm{E} 2$, the $\mathrm{OH}$ on $\mathrm{C} 17$, also participates in an 
important H-bond with His524. Initially, the hydrogens are placed such that the Hbond network is disrupted. The hydrogens on $\mathrm{E} 2$ and $\mathrm{HOH}$ were adjusted (as shown in Figure 14) to approximate the ideal H-bond network.

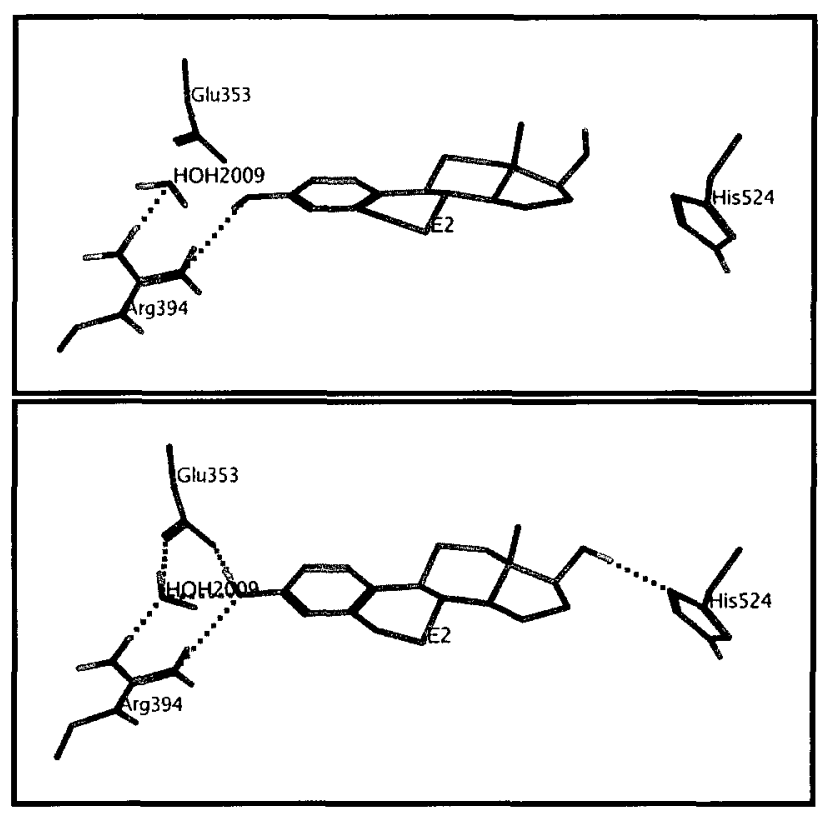

Figure 14: Hydrogen positions as added by default in MOE (top). Manually adjusted hydrogens on $\mathrm{E} 2$ and $\mathrm{HOH}$ to approximate the ideal H-bond network (lower).

The prepared complex was then energy minimized to remove the hydrogen clashes and optimize bond lengths, angles and protein dihedral angles for the force field. Our in-house program H_pdb_thaw which was written in MOE's Scientific Vector Language (SVL) was used to perform energy minimizations and create shells. Protein shells were defined to reduce computation time as well as to accommodate the docking protocol. A protein shell was defined as being the residues within a certain distance from the ligand. All residues with at least one atom within $6 \AA$ of the ligand were defined as the first shell, S1. The second shell, S2, was defined as the residues outside the S1 shell and having at least one atom closer than $12 \AA$ from the ligand. The remaining residues were all deleted and the broken bonds were capped with hydrogen atoms. 
Thẹse 'capping' hydrogen atoms were labeled, S3 (See Figure 15).

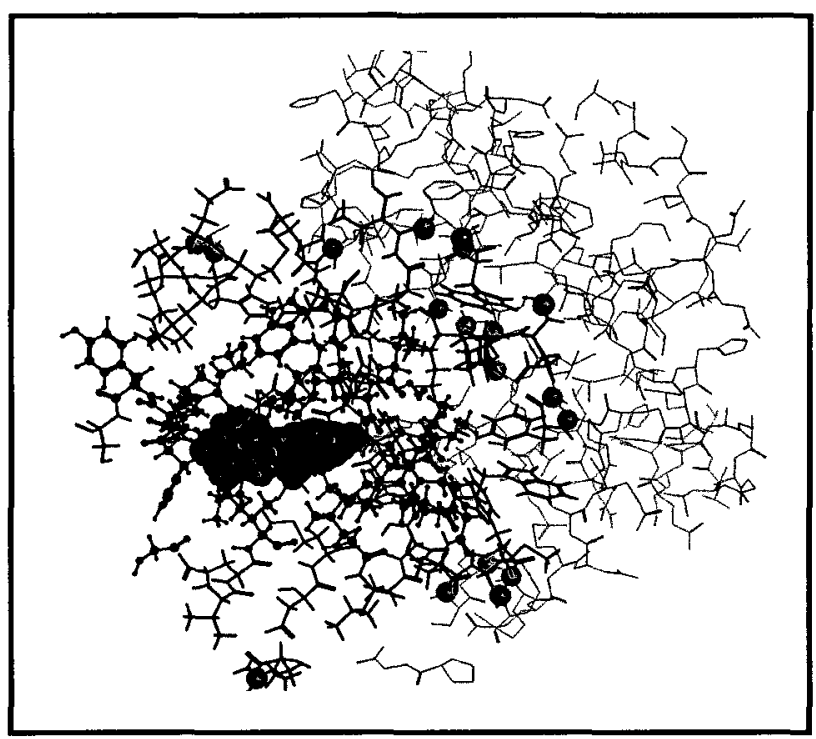

Figure 15: The shells of the receptor coloured with red (ligand), green (S1), blue (S2), orange (S3) and grey (discarded atoms).

$\mathrm{S} 1$ included all the active site atoms, containing 45 residues (664 atoms), S2 included 84 residues (1295 atoms) and S3 contained 25 atoms. The full monomer B contains around 4000 atoms, so the protein has been effectively reduced to half its previous size.

The thawing program attempts to reduce the distortion on the ligand and active site of the protein by initially keeping those atoms virtually fixed using strong tethers. Tethers are artificial parabolic potentials of the form $\mathrm{kdx}_{\imath}^{2}$, where $\mathrm{dx}_{\imath}$ is the displacement from the initial atomic coordinate $\mathrm{x}_{\imath}$ and $\mathrm{k}$ is the tether constant. The minimization starts with outer atoms having low tether and inner atoms strongly tethered. The next step of minimization has lowered tethers. After each round of minimization, the tethers are gradually lessened, starting from the outer atoms. All tethers were removed for the last round of minimization to create a fully thawed crystal structure in the MMFF94s force field. 
Although the next step was not necessary for the docking procedure or calculation of the required energy terms, it was useful in the analysis of the docked poses (DPs). A graphical representation of the surface of the active site was created using MOE. The ligand atoms, bound inside the receptor active site, were selected and the MOE option: Compute||Surfaces and Maps||Interaction(VdW). The image below (Figure 16) shows the generated active site.

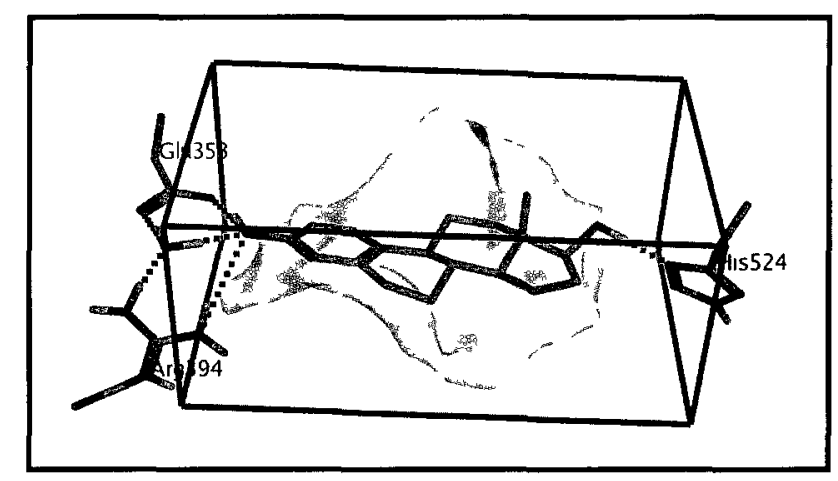

Figure 16: The active site surface as rendered by MOE in grey and the docking box defining the active site area with a few Angstrom buffer drawn in red lines.

In order to speed up docking, a docking box was also defined. This is an area of the protein in which the docking ligands are to be placed. This allows the docking program to ignore the irrelevant parts of the protein and only focus on the defined area of interest. A docking box was created that surrounded the whole active site, with a few angstroms buffer space in each direction (Figure 16).

\subsubsection{Ligand Preparation}

The compounds examined in this work are variants of the basic A-CD structure. That is, they are the standard steroid backbone with the B-ring removed. For ease of comparison between $\mathrm{E} 2$ and these compounds, the carbon atom numbering is the same as that of the standard steroid ring numbering. The stereochemistry of all 
stereo centers in A-CD is the same as E2, except at C14, where the hydrogen faces up. These compounds are labeled the 'cis' series, since the C14 hydrogen faces in the same direction as the methyl. The 'trans' A-CD series contains compounds with the C14 hydrogen facing down. The A-ring was modified by adding substituents at positions 2, 4 and 5 on the A-ring. These substituents included $\mathrm{F}, \mathrm{Cl}, \mathrm{CH}_{3}$ and $\mathrm{CF}_{3}$. The compounds labeled 1a-11 and 1o have a hydroxyl group at C17, as in E2, while compound $1 \mathrm{p}$ has a carbonyl group at C17, as in estrone. Compound $1 \mathrm{q}$ has the C17 hydroxyl and also contains a 17-ethynyl group. There are also three compounds with inverted chirality at C9 (2a, 2e, 2f), four compounds with a double bond in the C-ring between C8 and C9 (3a, 3b, 3e, 3f) and four with a double bond between C9 and C11 (4a, 4b, 4e, 4f). The structures can be seen in the image below (Figure 17).

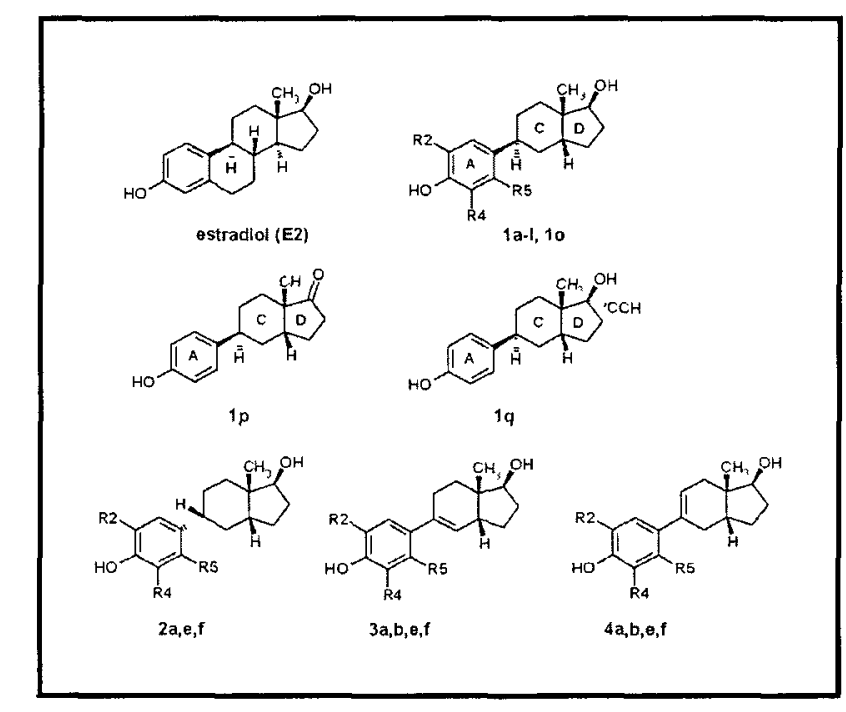

Figure 17: Structures and numbering scheme for A-CD compounds.

All of the experimental binding data are measured relative to the binding affinity of estradiol. The relative binding affinities (RBAs) were all gathered using the same procedure at the same lab, which gives consistency across the data. The RBAs were determined by a competitive radiometric binding assay using estradiol as the 
standard [55, De Angelis et al 2005]. For a full listing of the compounds, their substituents and their experimental RBAs, see Table 4. The set of compounds has binding affinities ranging from very poor binders to strong binders, almost 5 orders of magnitude, which will be acceptable for testing a SF.

\begin{tabular}{|c|c|c|c|c|}
\hline Compound & $\mathrm{R} 2$ & R4 & R5 & RBA $\alpha(\%)$ \\
\hline $\mathrm{E} 2$ & - & - & - & 10000 \\
\hline $1 \mathrm{a}$ & $\mathrm{H}$ & $\mathrm{H}$ & $\mathrm{H}$ & $147(026)$ \\
\hline $1 b$ & $\mathrm{H}$ & $F$ & $\mathrm{H}$ & $104(020)$ \\
\hline $1 \mathrm{c}$ & $\mathrm{H}$ & $\mathrm{H}$ & $\mathrm{F}$ & $273(069)$ \\
\hline $1 d$ & $\mathrm{H}$ & $\mathrm{H}$ & $\mathrm{Cl}$ & $523(120)$ \\
\hline $1 e$ & $\mathrm{H}$ & $\mathrm{H}$ & $\mathrm{Me}$ & $282(045)$ \\
\hline $1 \mathrm{f}$ & $\mathrm{H}$ & $\mathrm{H}$ & CF3 & $897(140)$ \\
\hline $1 \mathrm{~g}$ & $\mathrm{~F}$ & $\mathrm{~F}$ & $\mathrm{H}$ & $0040(0002)$ \\
\hline $1 \mathrm{~h}$ & $\mathrm{Cl}$ & $\mathrm{Cl}$ & $\mathrm{H}$ & $0004(0001)$ \\
\hline $1 \mathbf{i}$ & $\mathrm{H}$ & $\mathrm{F}$ & $\mathrm{F}$ & $462(093)$ \\
\hline $1 \mathrm{j}$ & $\mathrm{F}$ & $\mathrm{H}$ & $\mathrm{F}$ & $0380(0090)$ \\
\hline $1 k$ & $\mathrm{~F}$ & F & F & $0186\left(\begin{array}{lll}0 & 010\end{array}\right)$ \\
\hline 11 & $\mathrm{H}$ & $\mathrm{Me}$ & $\mathrm{H}$ & $175(050)$ \\
\hline 10 & $\mathrm{H}$ & $\mathrm{Cl}$ & $\mathrm{H}$ & $0065(0001)$ \\
\hline $1 p$ & $\mathrm{Cl}$ & H & $\mathrm{Cl}$ & $0008(0001)$ \\
\hline Iq & $\mathrm{H}$ & $\mathrm{Me}$ & $\mathrm{Me}$ & $0088(0006)$ \\
\hline $2 a$ & $\mathrm{H}$ & $\mathrm{H}$ & $\mathrm{H}$ & $0061(0002)$ \\
\hline $2 \mathrm{e}$ & $\mathrm{F}$ & $\mathrm{F}$ & $\mathrm{H}$ & $0006(0001)$ \\
\hline $2 f$ & $\mathrm{Cl}$ & $\mathrm{Cl}$ & $\mathrm{H}$ & $0004(0001)$ \\
\hline $3 a$ & $\mathrm{H}$ & $\mathrm{H}$ & $\mathrm{H}$ & $0246\left(\begin{array}{ll}0 & 02\end{array}\right)$ \\
\hline $3 b$ & $\mathrm{H}$ & $\mathrm{H}$ & $\mathrm{Cl}$ & $195(35)$ \\
\hline $3 e$ & $\mathrm{~F}$ & $\mathrm{H}$ & $\mathrm{F}$ & $0038(0005)$ \\
\hline $3 f$ & $\mathrm{H}$ & $\mathrm{H}$ & $\mathrm{CF} 3$ & $189\left(\begin{array}{ll}1 & 0\end{array}\right)$ \\
\hline $4 a$ & $\mathrm{H}$ & $\mathrm{H}$ & $\mathrm{H}$ & $0415(008)$ \\
\hline $4 b$ & $\mathrm{H}$ & $\mathrm{H}$ & $\mathrm{Cl}$ & $599(79)$ \\
\hline $4 e$ & F & $\mathrm{H}$ & $\mathrm{F}$ & $0436(008)$ \\
\hline $4 f$ & $\mathrm{H}$ & $\mathrm{H}$ & CF3 & $122(17)$ \\
\hline
\end{tabular}

Table 4: Experimental values of relative binding affinities (RBAs) for the full set of cisA-CD ligands bound to ER $\alpha$. Error bars in parentheses.

There were also several trans- compounds used in this work, in addition to the series of cus- compounds. There are 7 in total, 5 from the trans- 1 series and 2 from the trans- 4 series. The complete list, using an equivalent numbering scheme, is as follows: 1b-t, 1c-t, 1e-t, 1f-t, 1i-t, 4b-t and 4c-t. The experimental binding affinities 
are shown in Table 5 below.

\begin{tabular}{ccccc}
\hline Compound & R2 & R4 & R5 & RBA $\alpha(\%)$ \\
\hline \hline 1b-t & H & F & H & 17 \\
1c-t & H & H & F & 42 \\
1e-t & H & H & Me & 0.47 \\
1f-t & H & H & CF3 & 48 \\
1i-t & H & F & F & 092 \\
4b-t & H & H & Cl & 97 \\
4c-t & H & H & F & 218
\end{tabular}

Table 5: Experimental values of relative binding affinities (RBAs) for the trans- '-t' A-CD ligands bound to ER $\alpha$. 
Having defined the set of compounds to be docked, the next step was to generate the 3D structures This was done in MOE, bulding each framework and adding the appropriate substituents A database containing conformers of each compound was generated using the systematic conformer search feature avalable in MOE All rotatable bonds were systematically rotated by 20 degrees and each conformer was energy-minımized All redundant conformers were removed, leaving a docking input database containing 6 - 12 conformers of each compound

\subsubsection{Docking Protocol}

The docking algorithm takes each ligand conformer and places it in the center of the docking box that was defined previously Then the conformer is given a randomly generated rotation and translation If the conformer still remained inside the docking box the initial energy of the complex and interaction with the S1 shell was calculated The complex was then partially energy-minimized and the energy terms re-calculated Finally, the complex was minımized fully and the final energy terms were calculated In each minimization, the ligand and S1 shell atoms were unconstrained, S2 shell atoms were tethered and S3 shell atoms fixed Th1s procedure is repeated untıl 50 poses have been saved for each conformer, resulting in 500-1000 DPs per ligand

Once a pose was selected and fully minımized, there were several energy terms that wore calculated The first term measured was the energy of the ligand in that particular pose The energy of the receptor was approximated by calculating the energy of the S1 shell and the energy of interaction between the ligand and the S1 shell was also measured These were combined with several other energy terms to generate the iterative SF that will be discussed later on

The detals of how the force-field energy terms were calculated follows As stated above, the energy of the docked ligand pose in complex was measured $\left(\mathrm{E}_{L}{ }_{L}\right)$ as well as the lowest energy conformer of the free ligand $\left(\mathrm{E}_{L}\right)$ These two terms were combined 
to calculate the change in internal ligand energy upon binding to the receptor, $\Delta \mathrm{E}_{L}=\mathrm{E}_{L}^{\prime}-\mathrm{E}_{L}$. It should be noted that $\mathrm{E}_{L}^{\prime}$ only takes into account the internal energy of the ligand and disregards the interactions with the receptor. In effect, this is calculating how far above the lowest energy conformer is the particular pose in question. Another way of looking at this is that the term $\Delta E_{L}$ is actually a calculation of the deformation penalty that must be paid to bind the ligand in this pose. For this particular ligand set the $\Delta \mathrm{E}_{L}$ values ranged from $3-8 \mathrm{kcal} / \mathrm{mol}$ for good poses. The energy of the receptor in complex $\left(\mathrm{E}_{R}^{\prime}\right)$ was approximated by taking the energy of the $\mathrm{S} 1$ shell of the protein. A true value of $\Delta \mathrm{E}_{R}$ should include a measurement of the lowest energy value of the free receptor $\left(\mathrm{E}_{R}\right)$ as well, but since it will remain constant for all DPs, we have arbitrarily set it to be 330 $\mathrm{kcal} / \mathrm{mol}$. This gave a range of $\Delta \mathrm{E}_{R}$ values starting around $30-60 \mathrm{kcal} / \mathrm{mol}$ for good poses. The interaction energy between the ligand and the receptor $\left(\mathrm{E}_{\text {int }}\right)$ was measured and constituted the third term in the SF. Good poses of E2 docked into the receptor produced values of $E_{\text {int }}$ around $-73 \mathrm{kcal} / \mathrm{mol}$. The last term used in the scoring function was the energy of de-solvating the ligand from water. This term was calculated in Gaussian 03 with geometry optimized using B3LYP/6-31G(d) level. The conductor-like polarisable continuum model (CPCM) was selected in a second step with the parameters, HF/6-31G(d) SCRF=(CPCM, READ, SOLVENT=WATER) in the first line and PCMDOC, RADII=UAHF and SCFVAC at the end of the input file. Contained in the output file was the fourth energy term, $\Delta \mathrm{G}_{\text {solv }}$.

Iteration toward finding an optimum SF using the four energy terms described above began with finding the 'best' DP for each ligand. Each pose was analyzed using the London $\mathrm{dG}$ scoring function which is the default in MOE. The poses were then rank ordered based on this SF. The top pose for each ligand was chosen to be the one with the most negative value of the London $\mathrm{dG}$ score. The four energy terms for each of these 'best' poses were used in generating the first optimized SF. This was done by 
performing a multiple linear regression (MLR) over each of the independent variables (the energy terms) with respect to the log of the binding affinity, the dependent variable. The result of the MLR was a SF with coefficients for each energy term optimized to reproduce the experimental binding affinity with the form of:

$$
\log R B A_{(\text {pred })}=S F=C_{1}+C_{2}\left(E_{\text {int }}\right)+C_{3}\left(\Delta E_{L}\right)+C_{4}\left(\Delta E_{R}\right)+C_{5}\left(\Delta G_{\text {solv }}\right)
$$

All poses were re-evaluated with the new SF and ordered once more. The new 'best' poses were selected and the regression was performed on this new ligand set. The second iteration SF was again used to evaluate the DPs. This process continued until convergence was reached, which was defined as no further changes in the SF upon subsequent iterations. This process resulted in an iteratively optimized scoring function that could be used to predict binding affinities for docked poses.

To be able to see the predictive ability of the optimized scoring function, the set of ligands will be split into a training set and a separate test set. A 17 ligand training set was selected from the 27 ligands listed in Table 4. The training set contained the reference ligand $\mathrm{E} 2$, the parent compound $1 \mathrm{a}$ and 15 other ligands chosen to include a representative set of high $(>10 \%)$, medium $(0.1-10 \%)$ and low $(<0.1 \%)$ RBAs. An additional criterion for the training set was that it must include compounds from each set of structure types. The first structure type was A-CD with a saturated C-ring (1a - 1q), those with unsaturated C-rings (the 3- and 4-series) and those with inverted stereochemistry at C9 (the 2- series). The remaining 10 compounds made up the test set. These criteria were used to create four different test sets and their respective training sets.

The scoring function was tested by docking the test set and calculating the predicted $\log$ RBA using the optimized final SF for each of the DPs resulting from the docking. The top ranked poses based on this SF were then selected as the best pose 
and the predicted binding affinity was correlated to the experimental log RBAs. A good correlation indicates that the SF has predictive value for those compounds. This process was performed for each definition of the training and test sets.

A second test was performed to see if randomized, or nonsense, experimental data could also produce a correlation that appeared reasonable. The data was randomized by scrambling all of the log RBA values for each compound. This was accomplished by randomly swapping log RBA values until each compound had a different log RBA assigned to it. To ensure that the random process did not accidentally roughly correlate to the true values, the $\log \mathrm{RBA}_{\text {expt }}$ were correlated with the new $\log \mathrm{RBA}_{\text {scrambled }}$ and they had no significant correlation. The iterative procedure was again performed on the new scrambled training set to test convergence. 


\section{Chapter 3}

\section{Results and Discussion}

\subsection{Part I. Substituent Effects}

The compounds examined here all have one feature in common, that is they are all derived from phenol. They only difference is in the type, position and number of substituents. This difference, however, gives rise to the varying strength of the phenolic $\mathrm{OH}$ bond, measured as the $\triangle \mathrm{BDE}$. There are five different positions that a substituent might be placed on a mono-substituted phenol. The five different positions are displayed in Figure 18 for a mono-fluorinated phenol. For ortho-fluorinated phenol, the 'toward' position is the lowest energy state. The 'away' position is also a potential minimum, but the internal $\mathrm{OH}-\mathrm{F}$ hydrogen bond is only possible in the 'toward' position. Although reduced in strength from an optimally oriented H-bond, it still plays a significant role in stabilizing the compound. A linear water-HF dimer $\mathrm{H}$-bond has a strength of around $10 \mathrm{kcal} / \mathrm{mol}$ [56, Kollman and Allen 1969] in gas phase, thus even a severe reduction in that interaction due to the bent conformation still leaves a significant interaction.

Although there is no internal H-bonding in the meta positions, each position is different due to long-range interactions. There is only one arrangement possible for the para substituent, giving a total of five positions. 


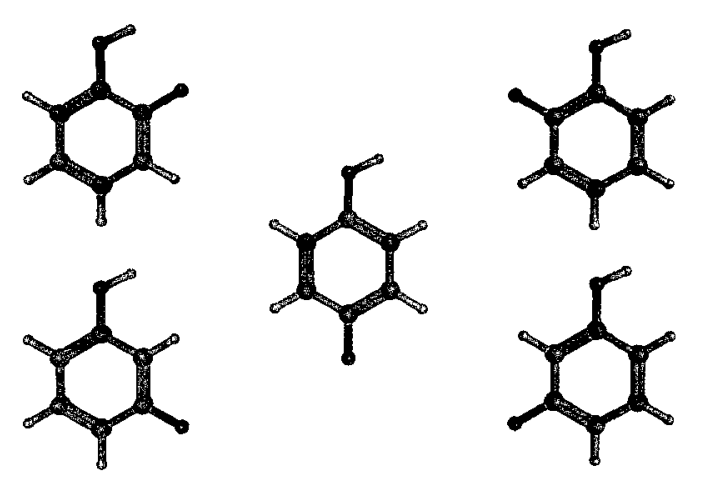

Figure 18: Possible positions for mono-fluormated phenols 'Top left, ortho 'toward', top right, ortho 'away', middle, para, bottom left, meta 'toward', bottom right, meta 'away'

\subsubsection{Training Set}

Since the BDE value changes with each different substituent arrangement, $\mathrm{BDE}_{O H}$ values were calculated for each compound using the MLM2 method, described in Methods The differences in values, or $\triangle B D E s$, were also calculated and these values are recorded in Table 6 for compounds that were exclusively fluormated, chlormated or brominated The calculated BDE value for unsubstituted phenol was $8748 \mathrm{kcal} / \mathrm{mol}$ This agrees well with the gas-phase value of $872 \pm 01 \mathrm{kcal} / \mathrm{mol}$ reported by $\mathrm{N} 1 \mathrm{x}$ et al $\left[15, N_{1 x} 2006\right]$

Now we shall look at the effect of substituents added to each position, starting with the ortho position Although halogens are usually classified as electron withdrawing groups (EWG), when in the ortho position on a phenol, a halogen typically acts as a classical electron donor by lowering the $\mathrm{BDE}_{O H}$ This can be seen by the $\triangle \mathrm{BDE}$ values for ortho-F phenol (away) of $-176 \mathrm{kcal} / \mathrm{mol}$, ortho- $\mathrm{Cl}$ ph (away) of $-146 \mathrm{kcal} / \mathrm{mol}$ and ortho-Br ph (away) of $-135 \mathrm{kcal} / \mathrm{mol}$ However, something changes when looking at the ortho-halogen (toward) conformations The $\triangle B D E$ values increase for toward ortho-halogenated phenols For example, o-F ph (toward) has 


\begin{tabular}{cccccccc}
\hline Compound & Position & F BDE & Cl BDE & Br BDE & F $\triangle$ BDE & Cl $\triangle$ BDE & Br $\triangle$ BDE \\
\hline Phenol & NA & 8748 & 8748 & 8748 & $\mathbf{0 . 0 0}$ & $\mathbf{0 . 0 0}$ & $\mathbf{0 . 0 0}$ \\
Ph 2 X & toward & 8846 & 8924 & 8938 & $\mathbf{0 . 9 8}$ & $\mathbf{1 . 7 6}$ & $\mathbf{1 . 9 0}$ \\
Ph 2 X & dway & 8572 & 8602 & 8613 & $-\mathbf{1 . 7 6}$ & $\mathbf{- 1 . 4 6}$ & $\mathbf{- 1 . 3 5}$ \\
Ph 3 X & toward & 8831 & 8849 & 8844 & $\mathbf{0 . 8 3}$ & $\mathbf{1 . 0 1}$ & $\mathbf{0 . 9 6}$ \\
Ph 3 X & away & 8848 & 8848 & 8840 & $\mathbf{1 . 0 0}$ & $\mathbf{1 . 0 0}$ & $\mathbf{0 . 9 2}$ \\
Ph 4 X & NA & 8546 & 8620 & 8644 & $\mathbf{- 2 . 0 2}$ & $\mathbf{- 1 . 2 8}$ & $\mathbf{- 1 . 0 4}$ \\
Ph 2,6 X & toward & 8694 & 8784 & 8805 & $\mathbf{- 0 . 5 4}$ & $\mathbf{0 . 3 6}$ & $\mathbf{0 . 5 7}$ \\
Ph 2,4 X & toward & 8658 & 8783 & 8811 & $\mathbf{- 0 . 9 0}$ & $\mathbf{0 . 3 5}$ & $\mathbf{0 . 6 3}$ \\
Ph 2,4 X & away & 8391 & 8468 & 8491 & $\mathbf{- 3 . 5 7}$ & $\mathbf{- 2 . 8 0}$ & $\mathbf{- 2 . 5 7}$ \\
Ph 3,4 X & toward & 8606 & 8708 & 8725 & $\mathbf{- 1 . 4 2}$ & $\mathbf{- 0 . 4 0}$ & $\mathbf{- 0 . 2 3}$ \\
Ph 3,4 X & away & 8623 & 8703 & 8717 & $\mathbf{- 1 . 2 5}$ & $\mathbf{- 0 . 4 5}$ & $\mathbf{- 0 . 3 1}$ \\
Ph 3,5 X & NA & 8961 & 8958 & 8944 & $\mathbf{2 . 1 3}$ & $\mathbf{2 . 1 0}$ & $\mathbf{1 . 9 6}$ \\
Ph 2,3 X & toward & - & 8991 & 9000 & $\mathbf{- -}$ & $\mathbf{2 . 4 2}$ & $\mathbf{2 . 5 2}$ \\
Ph 2,3 X & away & -- & 8654 & 8644 & -- & $\mathbf{- 0 . 9 4}$ & $\mathbf{- 1 . 0 4}$ \\
Ph 2,6,4 X & toward & 8519 & 8638 & 8667 & $\mathbf{- 2 . 2 9}$ & $\mathbf{- 1 . 1 0}$ & $\mathbf{- 0 . 8 1}$ \\
Ph 3,5,4 X & NA & 8715 & 8799 & -- & $\mathbf{- 0 . 3 3}$ & $\mathbf{0 . 5 1}$ & $\mathbf{- -}$
\end{tabular}

Table 6: Calculated BDEs for phenols exclusively halogenated $(\mathrm{F}, \mathrm{Cl}, \mathrm{Br})$. Values in $\mathrm{kcal} / \mathrm{mol}$.

a $\triangle B D E$ of $098 \mathrm{kcal} / \mathrm{mol}$ which is $2.74 \mathrm{kcal} / \mathrm{mol}$ larger than the away $\triangle \mathrm{BDE}$ of -1.76 kcal/mol. This can be explained by an internal H-bond that stabilizes the phenol. This will effectively raise the $\mathrm{BDE}_{O H}$ since the $\mathrm{H}$-bond stabilizes the parent molecule. The internal $\mathrm{H}$-bond raises the BDE to such a degree that it actually reverses the trend from decreasing to increasing the $\mathrm{BDE}_{O H}$. It can be seen that the $\mathrm{OH}-\mathrm{F}$ internal H-bond must make up the difference between toward and away conformers. This allows us to calculate the contribution of the H-bond by difference in the two conformers. Thus, the calculation of the internal ortho-F H-bond was found to be $2.74 \mathrm{kcal} / \mathrm{mol}$. Similarly, the internal H-bonds for ortho-Cl and ortho-Br are 3.21 and $3.25 \mathrm{kcal} / \mathrm{mol}$, respectively At first it would seem odd that the most electronegative atom, fluorine, does not have the strongest H-bond. However, Baker and Kaeding observed this phenomenon in a publication in 1959. They found that the H-bonding of ortho-halophenols was strongest for $\mathrm{Br}$, then $\mathrm{Cl}$ and finally $\mathrm{F}$ [57, Baker and Kaeding $1959]$. 
This toward/away problem at the ortho position complicates calculation of substituent constants It is common in literature to see discussions only for meta- and para-substıtuents [14, Chandra 2002] [16, Zhang 2001] [58, Bean 2002] Instead, the constant for ortho is often approxımated from the para substituent constant [59, Charton 1960]

The meta-halogenated phenols do not have the possibility of forming internal $\mathrm{H}$ bonds Although this does make them simpler to deal with, there is still a small difference between toward and away conformations The $\triangle \mathrm{BDE}$ value for meta-F phenol is $+083 \mathrm{kcal} / \mathrm{mol}$ for toward and $+100 \mathrm{kcal} / \mathrm{mol}$ for the away position, for a difference of $017 \mathrm{kcal} / \mathrm{mol}$ The phenoxyl radical formed is identical in both cases, so the difference must come from the parent phenol conformations The difference in $\triangle B D E$ s can be explained by aligning of $\mathrm{O}-\mathrm{H}$ and $\mathrm{C}-\mathrm{X}$ dipoles in the away position, thus stabllizing the parent and raising the $\mathrm{BDE}_{O H}$

Both $\mathrm{Cl}$ and $\mathrm{Br}$ had much smaller variation between toward and away conformations, with differences of only 001 and $003 \mathrm{kcal} / \mathrm{mol}$, respectively In each case the differences between the two meta conformations are small enough to permit us to assume there is only a single type of meta-substituent The average meta-substituent effects are $+091,+100$ and $+094 \mathrm{kcal} / \mathrm{mol}$ for $\mathrm{F}, \mathrm{Cl}$ and $\mathrm{Br}$ respectively In each case, the BDEs are being increased by adding a halogen to the meta position by approximately the same degree This is the effect that is seen from classical electronwithdrawing groups This is what was expected, as inductive effects form the primary contribution to the meta substituent effects and halogens are EWGs inductively

As mentioned previously, the para position has no H-bonding potential and only one conformation The calculated $\triangle \mathrm{BDEs}$ for $\mathrm{F}, \mathrm{Cl}$ and $\mathrm{Br}$ respectively are -202 , -128 and $-104 \mathrm{kcal} / \mathrm{mol}$ In each case, the halogens are lowerng the $\mathrm{BDE}_{O H}$ in the way typical of a classical electron-donating group, which was the effect that was expected for the para position Halogens have EDG resonance effects and the para 
position has contributions from both inductıve and resonance effects

The calculated monohalogenated $\triangle \mathrm{BDE}$ values are collected below along with the experimental values contained in Table 3 in the Introduction

\begin{tabular}{cccc}
\hline Calculated & Fluorine & Chlorine & Bromine \\
\hline ortho & -168 & -142 & -135 \\
meta & 102 & 102 & 097 \\
para & -202 & -139 & -104 \\
Experımental & Fluorine & Chlorine & Bromine \\
\hline ortho & $-19( \pm 2)$ & $-07( \pm 1)$ & $-17( \pm 2)$ \\
meta & $14( \pm 2)$ & $12( \pm 1)$ & - \\
para & $-10( \pm 1)$ & $-02( \pm 1)$ & $05( \pm 1)$
\end{tabular}

Table 7: Experimental and calculated $\triangle B D E$ values for monohalogenated phenols a Experimental $\triangle B D E s$ obtained from [17 Santes and Simoes 1998]

A quick look shows that the major trends between the calculated and experimental values are correct. In general, ortho halogens reduce the BDE, meta halogens increase the BDE and para halogens decrease the BDE Bromine is the exception for the para substituents as it actually increases the BDE However, the trend across the halogens at this position remains the same, with $\mathrm{F}<\mathrm{Cl}<\mathrm{Br}$ Finally, the resonance donor effect of $\mathrm{F}$ is about twice as strong as the other halogens [60, Swain and Lupton 1968], which can be seen in the lower calculated $\triangle \mathrm{BDEs}$ at the ortho and para positions $\mathrm{A}$ graph of the correlation between the calculated and experımental $\triangle B D E$ values for monohalogenated phenols shows that there is a moderate trend between the values (Figure 19) 


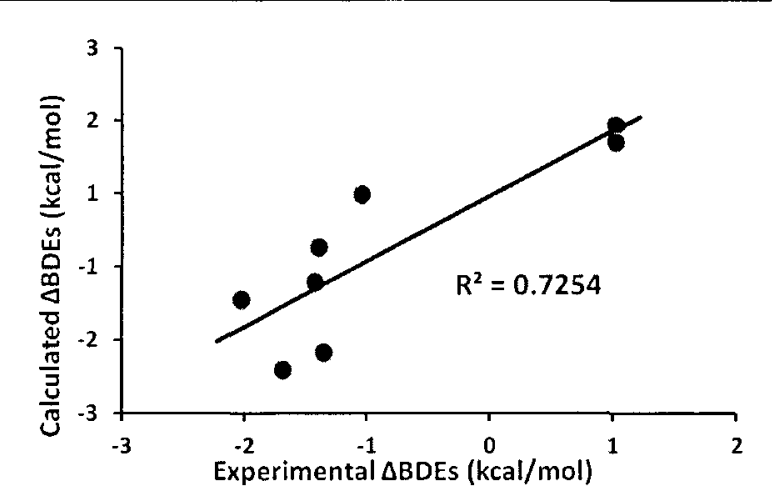

Figure 19: The correlation between experimental and calculated $\triangle \mathrm{BDE}_{O H}$ values shows the calculated values match.

Despite minor differences in trends, all of the calculated $\triangle B D E$ s fall within the uncertainties of the experimental $\triangle \mathrm{BDEs}$.

A general set of substituent constants were generated using multiple linear regression, producing a different equation for each halogen type. The independent variables were \# of H-bonds, \# of $o$-substituents, \# of $m$-substituents and \# of $p$-substituents and the dependent variable was the calculated $\triangle \mathrm{BDE}_{O H}$. Each equation must be calibrated using a training set of compounds, again, one training set for each halogen type. The training set chosen for fluorinated phenols included each of the 5 monofluorinated compounds from Figure 18, ortho, ortho- and meta, meta-difluorophenol as well as unsubstituted phenol. This gives a total of 8 compounds in the training set where $\triangle \mathrm{BDE}$ values were calculated for each compound using the B3LYP functional and basis sets as described in Methods. All equations were forced to have an intercept at zero to create equations that only depended on the substituent constants.

Each of the equations generated by the training sets is shown in Equations 27-29 and is also collected in Table 8 along with errors on parameters, $\mathrm{R}^{2}$ values and MADs. 


$$
\begin{aligned}
& \triangle B D E=2.74 * \#_{H-\text { bonds }}-1.68 * \#_{\text {ortho }-F}+1.02 * \#_{\text {meta-F }}-2.02 * \#_{\text {para-F }} \\
& \triangle B D E=3.19 * \#_{H-b o n d s}-1.42 * \#_{\text {ortho }-C l}+1.02 * \#_{\text {meta }-C l}-1.39 * \#_{\text {para }-C l} \\
& \triangle B D E=3.25 * \#_{H-b o n d s}-1.35 * \#_{\text {ortho- } B r}+0.97 * \#_{\text {meta }-B r}-1.04 * \#_{\text {para }} \text { Br }
\end{aligned}
$$

\begin{tabular}{lcccccccc}
\hline Halogen & Type & $\mathbf{n}$ & HB & ortho & meta & para & R2 & MAD \\
\hline Fluorine & Training & 8 & $274(018)$ & $-1.68(0.10)$ & $102(005)$ & $-202(013)$ & 09957 & 0.07 \\
Chlorine & Training & 8 & $319(006)$ & $-142(0.04)$ & $102(002)$ & $-139(003)$ & 09988 & 0.03 \\
Bromine & Training & 8 & $325(004)$ & $-1.35(0.02)$ & $097(001)$ & $-104(003)$ & 09998 & 0.01 \\
Fluorine & Expanded & 14 & -- & -- & - & -- & 09832 & 0.12 \\
Chlorine & Expanded & 16 & -- & -- & -- & -- & 09852 & 0.09 \\
Bromine & Expanded & 15 & -- & -- & - & - & 0.9687 & 014
\end{tabular}

Table 8: Parameter values and their associated errors for training and expanded sets using halogens of one type only, where $n=\#$ of data values. All values in $\mathrm{kcal} / \mathrm{mol}$. $\mathrm{MAD}=$ mean absolute deviation.

The equations generated from each of the training sets all fit the data extremely well, with correlation coefficients $\mathrm{R}^{2}>0.995$. The MADs are also very small when compared with the range of the $\triangle \mathrm{BDEs}$ contained in the training sets. The ranges of $\triangle \mathrm{BDEs}$ for the training sets are shown (Low - High): F (-2.02 - 2.13); Cl (-1.46 $2.10) ; \mathrm{Br}(-1.35-1.90)$. Thus, the fluorine training set has a range of $4.15 \mathrm{kcal} / \mathrm{mol}$ with a MAD of $0.07 \mathrm{kcal} / \mathrm{mol}$, which is $1.7 \%$. The chlorine training set had a range of $3.56 \mathrm{kcal} / \mathrm{mol}$ and a MAD of $0.03 \mathrm{kcal} / \mathrm{mol}$, or $0.8 \%$. The bromine training set had a range of $3.25 \mathrm{kcal} / \mathrm{mol}$ and a $\mathrm{MAD}$ of $0.01 \mathrm{kcal} / \mathrm{mol}$, which was $0.3 \%$.

The good quality of correlation coefficients and the low MAD values from the equations derived from the training sets indicate that they will be able to predict ${ }^{1}$ $\triangle \mathrm{BDE}_{O H}$ of halogenated phenols not contained in the training set.

\footnotetext{
${ }^{1}$ From now on, calculated will refer to $\triangle B D E s$ calculated in Gaussian using the B3LYP protocol and predicted will refer to $\triangle B D E$ s found using the equations derived from the training sets.
} 


\subsubsection{Expanded Set}

In order to test the generality of the equations and the additivity of the substituent constants, expanded sets of data were created using more substituents The parameters derived from the training sets were used to predict $\triangle B D E s$ in order to determine the additivity of the substituent constants The quality of the fit was measured by the MAD between the calculated and predicted $\triangle B D E$ s The compounds used in these tests were stıll exclusıvely halogenated, but contained combinatıons of dihalogenated, $o, o, p$ - and $m, m, p$-substituted compounds, which can also be found in Table 6 These expanded sets contained between 14 - 16 compounds, which included the training set compounds and had expanded $\triangle B D E$ spreads of F (-3 $57-213 \mathrm{kcal} / \mathrm{mol}), \mathrm{Cl}(-280$ - $242 \mathrm{kcal} / \mathrm{mol}), \operatorname{Br}(-257$ - $252 \mathrm{kcal} / \mathrm{mol})$ Although the MAD values increased in data set to 015,009 and $014 \mathrm{kcal} / \mathrm{mol}$ for $\mathrm{F}, \mathrm{Cl}$ and $\mathrm{Br}$ respectıvely, they are stıll significantly smaller than the data spread The fluorme expanded set had a data spread of $570 \mathrm{kcal} / \mathrm{mol}$ and a MAD of $015 \mathrm{kcal} / \mathrm{mol}$, or $26 \%$ The chlorine and bromine expanded sets had data spreads of 522 and $509 \mathrm{kcal} / \mathrm{mol}$ with MADS of 009 and $014 \mathrm{kcal} / \mathrm{mol}$, or $17 \%$ and $28 \%$ respectively In additıon to the excellent correlations from the training sets, with $\mathrm{R}^{2}$ values $>0995$, this expanded test demonstrates once more that the parameters obtained from the trainıng sets have good predictıve value and additivity

\subsubsection{Mixed Polyhalogenated Phenols}

Having established that the training set parameters could predict $\triangle B D E$ s for the expanded compounds, we now considered a more challenging problem Three sets of mixed compounds were bult containing combinations of double and triple substitutions on the phenol The first set contamed mixed $\mathrm{F}$ and $\mathrm{Cl}$ substituents, the second mixed $\mathrm{F}$ and $\mathrm{Br}$ substituents and the third mixed $\mathrm{Cl}$ and $\mathrm{Br}$ substituents The 
mixed double substituted phenols were comprised of combinations of ortho/para, ortho/ortho, meta/para and meta/meta substituents, with both toward and away conformations For example, ortho/para in the mixed $\mathrm{F}$ and $\mathrm{Cl}$ set had four conformers, $o-\mathrm{F}, p-\mathrm{Cl}$ phenol (toward and away) as well as $o-\mathrm{Cl}, p-\mathrm{F}$ phenol (toward and away). The triple substituted phenols were comprised of combinations of ortho/ortho/para and meta/meta/para using any two of the three halogens $(\mathrm{F}, \mathrm{Cl}, \mathrm{Br})$ used in this work. A full listing of the mixed polyhalogenated compounds can be seen in Table 9 , along with therr calculated and predicted $\triangle \mathrm{BDE}$ values.

\begin{tabular}{|c|c|c|c|c|c|c|c|}
\hline \multirow[b]{2}{*}{ Compound } & \multirow[b]{2}{*}{ H-bond } & \multicolumn{3}{|c|}{ Calculated $\triangle \mathrm{BDE}$} & \multicolumn{3}{|c|}{ Predıcted $\triangle B D E$} \\
\hline & & $\mathrm{F} / \mathrm{Cl}$ & $\mathrm{F} / \mathrm{Br}$ & $\mathrm{Cl} / \mathrm{Br}$ & $\mathrm{F} / \mathrm{Cl}$ & $\mathrm{F} / \mathrm{Br}$ & $\mathrm{Cl} / \mathrm{Br}$ \\
\hline Phenol & NA & 000 & 000 & 000 & 000 & 000 & 000 \\
\hline Ph 2,6 X & toward & -024 & -013 & - & -036 & -029 & - \\
\hline $\mathrm{Ph} 2,6 \mathrm{X}$ & away & 007 & 019 & - & 008 & 023 & - \\
\hline Ph $2,4 \mathrm{X}$ & toward & -028 & -012 & 054 & -033 & 002 & 072 \\
\hline Ph $2,4 \mathrm{X}$ & away & -296 & -279 & -262 & -307 & -272 & -247 \\
\hline $\mathrm{Ph}_{4,2} \mathrm{X}$ & toward & -026 & -014 & - & -026 & -011 & - \\
\hline$P_{4,2} \mathrm{X}$ & away & -339 & -328 & - & -344 & -337 & - \\
\hline $\mathrm{Ph} 3,4 \mathrm{X}$ & toward & -074 & -055 & - & -038 & -003 & - \\
\hline Ph 3,4 X & away & -058 & -040 & - & -038 & -003 & - \\
\hline Ph 4,3 X & toward & -114 & -119 & - & -100 & -105 & - \\
\hline Ph $4,3 \times$ & away & -115 & -124 & - & -100 & -105 & - \\
\hline $\mathrm{Ph}_{3,5 \mathrm{X}}$ & toward & 201 & 188 & 198 & 203 & 198 & 198 \\
\hline $\mathrm{Ph} 3,5 \mathrm{X}$ & away & 217 & 208 & 200 & 203 & 198 & 198 \\
\hline $\mathrm{Ph} 2,6 \mathrm{X} 4 \mathrm{Y}$ & toward & -177 & -162 & -096 & -201 & -166 & -071 \\
\hline $\mathrm{Ph} 2,4 \mathrm{X} 6 \mathrm{Y}$ & toward & -208 & -199 & -104 & -238 & -231 & -098 \\
\hline $\mathrm{Ph} 2,4 \times 6 \mathrm{Y}$ & away & -180 & -172 & - & -194 & -179 & - \\
\hline $\mathrm{Ph} 4 \mathrm{X} 2,6 \mathrm{Y}$ & toward & -161 & -143 & -094 & -168 & -146 & -083 \\
\hline $\mathrm{Ph} 6 \mathrm{X} \quad 2,4 \mathrm{Y}$ & toward & -128 & -102 & -088 & -131 & -082 & -056 \\
\hline $\mathrm{Ph} 6 \mathrm{X} \quad 2,4 \mathrm{Y}$ & away & -157 & -134 & -089 & -175 & -133 & -063 \\
\hline $\mathrm{Ph} 3,5 \mathrm{X} 4 \mathrm{Y}$ & toward & 021 & 041 & 073 & 064 & 099 & 099 \\
\hline $\mathrm{Ph} 3,4 \mathrm{X} 5 \mathrm{Y}$ & toward & -038 & -050 & 046 & 001 & -004 & 059 \\
\hline $\mathrm{Ph} 3,4 \mathrm{X} 5 \mathrm{Y}$ & away & -020 & -028 & 049 & 001 & -004 & 059 \\
\hline $\mathrm{Ph} 4 \mathrm{X} 3,5 \mathrm{Y}$ & toward & -018 & -031 & 042 & 002 & -009 & 054 \\
\hline $\mathrm{Ph} 5 \mathrm{X} 3,4 \mathrm{Y}$ & toward & 040 & 056 & - & 064 & 094 & - \\
\hline $\mathrm{Ph} 5 \mathrm{X} 3,4 \mathrm{Y}$ & away & 022 & 035 & - & 064 & 094 & - \\
\hline
\end{tabular}

Table 9: Calculated and predicted $\triangle \mathrm{BDEs}$ for mixed polyhalogenated $(\mathrm{F}, \mathrm{Cl}, \mathrm{Br})$ compounds All values in $\mathrm{kcal} / \mathrm{mol}$. 
The predicted $\triangle \mathrm{BDE}$ was calculated for each compound in the mixed dataset using the previously derived parameters. The $\triangle \mathrm{BDE}$ contribution from each type of substituent needed to be calculated and then summed together. For example, (toward) ortho-F, para-Cl phenol has one internal hydrogen bond with $\mathrm{F}$, one ortho- $\mathrm{F}$ substituent and one para-Cl substituent. Using parameters collected in Table 8 , the predicted $\triangle \mathrm{BDE}$ is,

$$
\Delta \mathrm{BDE}=\# \operatorname{HBs}(\mathrm{F})^{*} 2.74+\# \text { ortho }(\mathrm{F})^{*}-1.68+\# \text { para }(\mathrm{Cl})^{*}-1.39=-0.33
$$

This is quite close to the calculated value of $-0.28 \mathrm{kcal} / \mathrm{mol}$, with abs. dev. $=0.05$ $\mathrm{kcal} / \mathrm{mol}$. The predicted $\triangle \mathrm{BDEs}$ were calculated and stored in Table 9 along with their respective calculated $\triangle B D E$. The correlation between predicted and calculated $\triangle B D E$ is excollent, as seen in Figure 20.

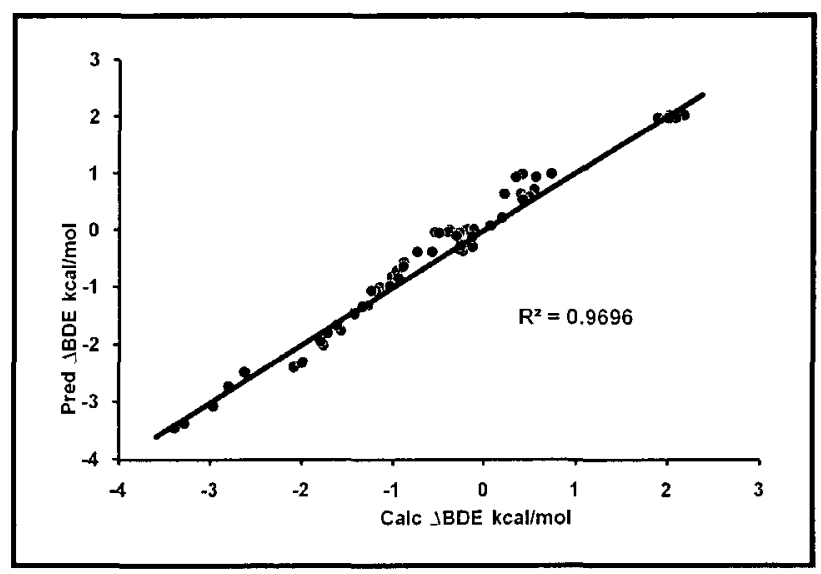

Figure 20: Correlation between predicted $\triangle B D E$ and calculated $\triangle B D E$ values for the mixed polyhalogenated phenols.

The other test for goodness of fit, the MADs, was also excellent. The MAD for the full $\mathrm{F} / \mathrm{Cl}$ set, which includes the training set, is $\mathrm{MAD}=0.18 \mathrm{kcal} / \mathrm{mol}$ which is in the order of the MADs of the training sets. The same process was performed for the $\mathrm{F} / \mathrm{Br}$ and $\mathrm{Cl} / \mathrm{Br}$ sets obtaining a $\mathrm{MAD}=0.21 \mathrm{kcal} / \mathrm{mol}$ for $\mathrm{F} / \mathrm{Br}$ and $0.15 \mathrm{kcal} / \mathrm{mol}$ for $\mathrm{Cl} / \mathrm{Br}$. When the MAD was calculated for the combined mixed sets, the total 
MAD was $0.18 \mathrm{kcal} / \mathrm{mol}$.

The results have demonstrated that the training set was well fitted using an MLR and the variables \# of H-bonds, \# of substituents of each position (ortho, meta, para) and type of substituent $(\mathrm{F}, \mathrm{Cl}, \mathrm{Br})$. The predicted $\triangle \mathrm{BDE}$ values were very well correlated with calculated values for polyhalogenated phenols when halogens are of the same type and these parameters also work even when different types of halogens are mixed together. This indicates excellent additivity of the substituent effects.

\subsection{Part II. Iterative Scoring Functions}

The 17 ligand training set contained the reference ligand E2, the parent compound 1a and 15 other ligands, was chosen as described in Methods and labeled Training Set 1 and the remaining 10 compounds made up Test Set 1 . The docking procedure performed on each conformer gave 16,172 docked poses for the training set and 9,186 DPs for the test set. Each pose in the training set was evaluated using the London $\mathrm{dG}$ scoring function and the 'best pose' for each ligand was chosen as having the most negative value of London dG. These 'best poses' were selected and shown in Table 10 showing the experimental log RBA values, the calculated London dG scores as well as the four energy terms $\mathrm{E}_{\text {int }}, \Delta \mathrm{E}_{L}, \Delta \mathrm{E}_{R}$ and $\Delta \mathrm{G}_{\text {solv }}$. Having selected the top ranked DPs based on the current London dG SF, the analysis can begin. The first issue that can be seen with these poses is that the $E_{\text {rnt }}$ values are significantly higher than the $-70 \mathrm{kcal} / \mathrm{mol}$ range that was expected, several $\Delta \mathrm{E}_{L}$ values are high (ie. $13.6 \mathrm{kcal} / \mathrm{mol}$ for 1c) and the range of $\Delta \mathrm{E}_{R}$ is also high (1o is as high as $74 \mathrm{kcal} / \mathrm{mol}$ ). 


\begin{tabular}{cccccccc}
\hline Ligand & $\log \mathbf{R B A}_{(\text {expt })}$ & $\mathbf{E}_{\text {rnt }}$ & $\Delta \mathbf{E}_{L}$ & $\Delta \mathbf{E}_{R}$ & $\Delta \mathbf{G}_{\text {solv }}$ & London $\mathbf{d G}$ & $\mathbf{S F}_{1}$ \\
\hline \hline $\mathbf{E 2}$ & 200 & -5389 & 611 & 6101 & -1240 & -1439 & 022 \\
1a & 017 & -5432 & 629 & 3654 & -1069 & -1357 & 093 \\
1b & 002 & -5285 & 687 & 3794 & -809 & -1393 & 043 \\
1c & 144 & -6204 & 1359 & 5144 & -1007 & -1424 & -054 \\
1e & 045 & -5809 & 577 & 4979 & -958 & -1359 & 043 \\
1f & 195 & -6522 & 412 & 5040 & 820 & -1494 & 061 \\
1h & -240 & -5673 & 997 & 5002 & -597 & -1403 & 065 \\
1k & -073 & -5976 & 751 & 5624 & -743 & -1463 & -030 \\
1l & 024 & -5630 & 725 & 4912 & -896 & -1442 & 014 \\
1o & -119 & -4703 & 970 & 7382 & -859 & -1441 & -141 \\
$\mathbf{1 p}$ & -210 & -5262 & 1259 & 5484 & -1115 & -1286 & -060 \\
$\mathbf{2 a}$ & -121 & -6219 & 977 & 5080 & -1175 & -1454 & 023 \\
2e & -222 & -5694 & 1084 & 7686 & -870 & -1526 & -144 \\
3e & -142 & -6049 & 650 & 4474 & -1232 & -1497 & 094 \\
3f & 228 & -5721 & 873 & 4093 & -898 & -1469 & 028 \\
4b & 178 & -5888 & 917 & 3351 & -945 & -1406 & 060 \\
4e & -036 & -4527 & 1282 & 6670 & -1167 & -1499 & -119
\end{tabular}

Table 10: Experımental $\log R B A$ values and calculated energy descriptor set $\left(\mathrm{E}_{\imath n t}, \Delta \mathrm{E}_{L}\right.$, $\Delta \mathrm{E}_{R}$ and $\Delta \mathrm{G}_{\text {solv }}$ ) for the 17 ligands in Training Set 1 Docked poses were taken from the top-ranked (most negatıve) values based on the London dG Scoring Function All energy values in $\mathrm{kcal} / \mathrm{mol}$

The MLR procedure was performed on Training Set 1 to generate the following $\mathrm{SF}$

$\mathrm{SF}_{1}\left(\log \mathrm{RBA}_{\text {pred }}\right)=0570-00225^{*} \mathrm{E}_{\text {ınt }}-0135^{*} \Delta \mathrm{E}_{L}-00387^{*} \Delta \mathrm{E}_{R}-0130^{*} \Delta \mathrm{G}_{\text {solv }}$ Giving the correlation coefficient $\mathrm{R}^{2}=0.245$ and std dev $=132 \log$ units The correlation is very weak (see Figure 21), which is supported by the poor correlation coefficient and the large standard deviation This could indicate several things, namely that the docking method/force-field model is unable to return physically significant results, that the energy terms used in the MLR only account for part of the story or that the 'best' poses selected by the initial scoring function were not truly that great 


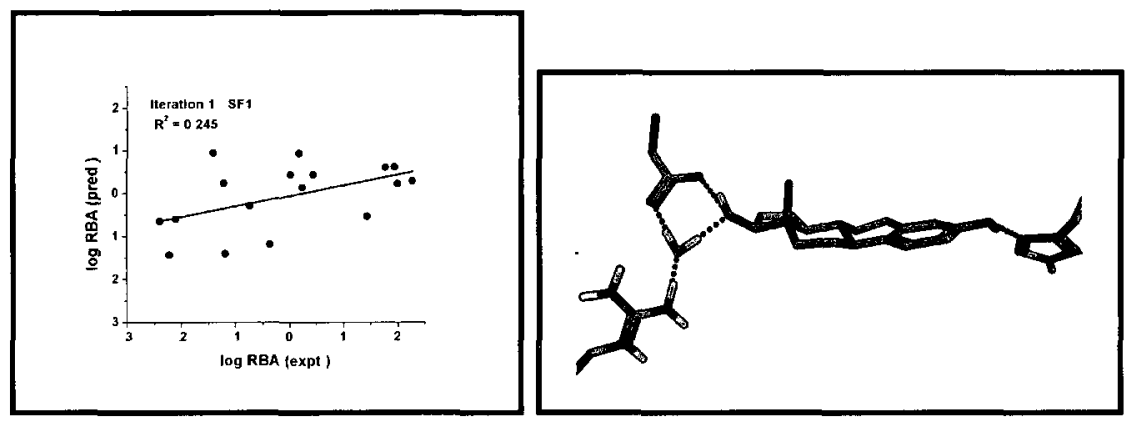

Figure 21: Initial correlation between predicted and experimental log RBA values for Training Set 1, based on an MLR over four energy terms and pose selection based on the London dG SF (left). Binding mode of E2, showing the top-ranked docked pose according to the London $\mathrm{dG}$ SF (right).

The second part of Figure 21 shows the top ranked binding mode of E2 as chosen using the London $\mathrm{dG}$ function. This binding mode is flipped $180^{\circ}$ from the crystal structure and so it is likely that the chosen pose is not a very good pose at all. A quick scan of the docked poses produces several other poses that appear to be significantly better visually and with much more negative $\mathrm{E}_{\text {ınt }}$ values.

The binding affinities for all DPs were calculated using $\mathrm{SF}_{1}$, the newly generated scoring function. The top pose, or the pose with the highest predicted RBA, was selected for each ligand. The new selection of top poses is contained in Table 11. 


\begin{tabular}{ccccccc}
\hline Ligand & log RBA $_{(e x p t)}$ & $\mathbf{E}_{2 n t}$ & $\Delta \mathbf{E}_{L}$ & $\Delta \mathbf{E}_{R}$ & $\Delta \mathbf{G}_{\text {solv }}$ & $\mathbf{S F}_{2}$ \\
\hline \hline E2 & 200 & -6811 & 295 & 2636 & -1240 & 139 \\
1a & 017 & -6464 & 488 & 1922 & -1069 & 022 \\
1b & 002 & -6047 & 530 & 2723 & -809 & 112 \\
1c & 144 & -6551 & 500 & 1959 & -1007 & 037 \\
1e & 045 & -6628 & 440 & 2317 & -958 & 066 \\
1f & 195 & -7135 & 616 & 2209 & -820 & 118 \\
1h & -240 & -5592 & 369 & 4000 & -597 & 195 \\
1k & 073 & 6504 & 504 & 2874 & 743 & 003 \\
1l & 024 & 6741 & 513 & 1948 & 896 & 080 \\
1o & -119 & 6429 & 682 & 3361 & -859 & 119 \\
1p & 210 & 5141 & 292 & 2635 & -1115 & 227 \\
2a & 121 & 6264 & 664 & 2569 & 1175 & -129 \\
2e & -222 & -6117 & 738 & 3573 & 870 & 222 \\
3e & 142 & 6219 & 474 & 2075 & -1232 & 041 \\
3f & 228 & -7531 & 561 & 1726 & -898 & 247 \\
4b & 178 & -7079 & 421 & 1554 & -945 & 209 \\
4e & -036 & -6859 & 725 & 2153 & 1167 & -001
\end{tabular}

Table 11: Docked poses for Training Set 1 re-ranked using the $\mathrm{SF}_{1}$ scoring function The most positive value of $\mathrm{SF}_{1}$ for each ligand was used to generate this table Energy values in $\mathrm{kcal} / \mathrm{mol}$

This data in the table clearly shows that there has been a general improvement in the selected 'best' poses chosen from the set of DPS $E_{\imath n t}$ values have been lowered from the previous range of -45 to $-62 \mathrm{kcal} / \mathrm{mol}$ to a more reasonable range of -51 to $-75 \mathrm{kcal} / \mathrm{mol}$ The same trend appears in both the $\Delta \mathrm{E}_{L}$ and $\Delta \mathrm{E}_{R}$ values, where they have much smaller deformation penalties These terms were used for the MLR procedure to produce a second scoring function, $\mathrm{SF}_{2}$, as follows

$\mathrm{SF}_{2}\left(\log \mathrm{RBA}_{\text {pred }}\right)=-1085-0223^{*} \mathrm{E}_{\text {rnt }}-0410^{*} \Delta \mathrm{E}_{L}-00446^{*} \Delta \mathrm{E}_{R}+00462^{*} \Delta \mathrm{G}_{\text {solv }}$ The correlation coefficient obtained was $\mathrm{R}^{2}=0853$ with a std $\mathrm{dev}=0582 \mathrm{log}$ units This is clcarly a much improved fit, without major outliers (see Figure 22)

The visual check on the binding mode for the 'best' $\mathrm{E} 2$ pose selected based on $\mathrm{SF}_{1}$ 


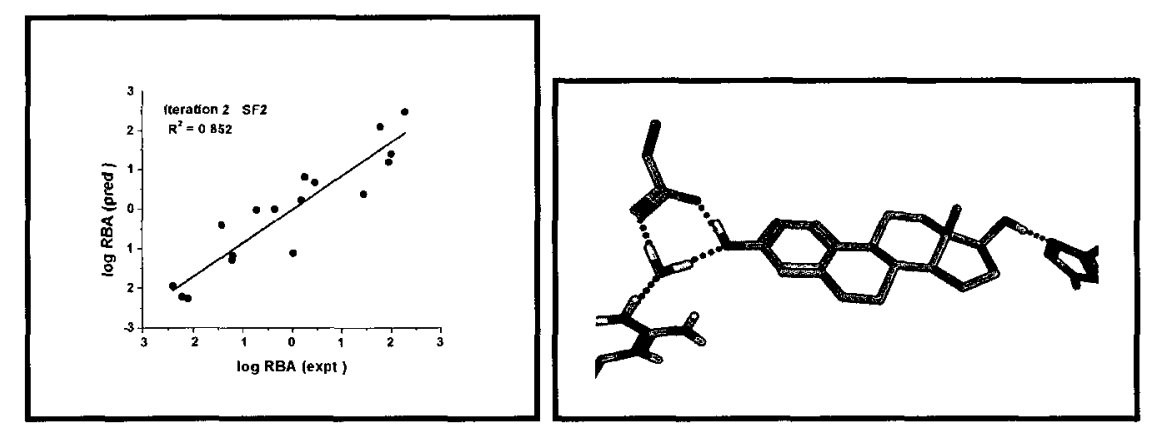

Figure 22: Correlation between the predicted $\log \mathrm{RBA}$ calculate using $\mathrm{SF}_{2}$ and the experimental $\log$ RBA values for Training Set 1 (left). Top-ranked binding mode of $\mathrm{E} 2$, as given by the top-ranked pose from $\mathrm{SF}_{2}$ (right).

shows that the pose is oriented correctly. There is a twist in the side chain of Arg394 that makes the H-bond with $\mathrm{E} 2$ less than ideal, but this is a significantly improved pose compared with the previous one.

The DPs were next re-ranked using $\mathrm{SF}_{2}$ and again an MLR was performed on the new set of 'best' poses. This was continued until the current scoring function was the same as the previous one, ie. $\mathrm{SF}_{n}=\mathrm{SF}_{n-1}$. The change of correlation coefficient $\mathrm{R}^{2}$ over iteration number is shown in Figure 23. It can be seen that the function approaches convergence around iteration 4 and has achieved it by iteration 8 .

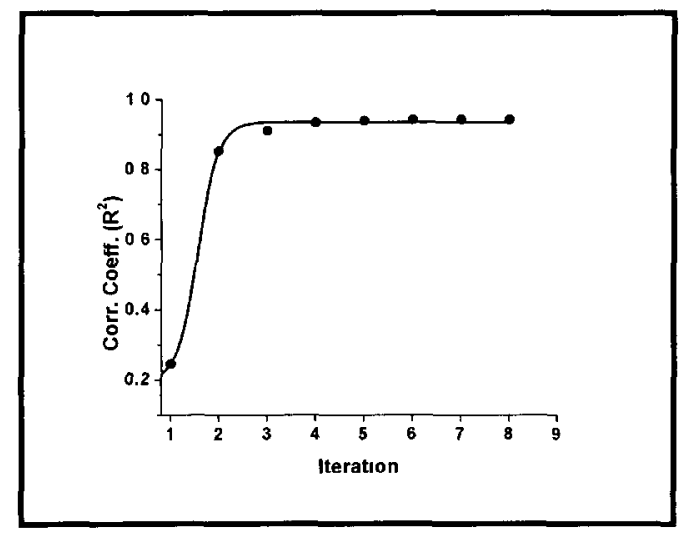

Figure 23: Change in correlation coefficient as a function of iteration number for Test Set 1. 
Not only does the process converge, but it has also reached an excellent correlation of $\mathrm{R}^{2}=0942$ and std $\mathrm{dev}=0365 \mathrm{log}$ unit The resulting scoring function is

$$
\mathrm{SF}_{8}\left(\log \mathrm{RBA}_{\text {pred }}\right)=-2423-0362^{*} \mathrm{E}_{\text {int }}-0413^{*} \Delta \mathrm{E}_{L}+00266^{*} \Delta \mathrm{E}_{R}+00268^{*} \Delta \mathrm{G}_{\text {solv }}
$$

The final set of poses was selected using $\mathrm{SF}_{8}$ and the terms are in Table 12 It can be seen that the interaction energies are much improved, with many values more negative than $-70 \mathrm{kcal} / \mathrm{mol}$ The values of $\Delta \mathrm{E}_{L}$ and $\Delta \mathrm{E}_{R}$ are also in an acceptable range with all $\Delta \mathrm{E}_{L}<10 \mathrm{kcal} / \mathrm{mol}$ and all $\Delta \mathrm{E}_{R}<66 \mathrm{kcal} / \mathrm{mol}$

\begin{tabular}{|c|c|c|c|c|c|c|}
\hline Ligand & $\log \mathbf{R B A}_{(e x p t)}$ & $\mathbf{E}_{\imath n t}$ & $\Delta \mathbf{E}_{L}$ & $\Delta \mathrm{E}_{R}$ & $\Delta \mathbf{G}_{\text {solv }}$ & $\mathrm{SF}_{8}$ \\
\hline $\mathrm{E} 2$ & 200 & -7323 & 322 & 4788 & -1240 & 192 \\
\hline $1 \mathbf{a}$ & 017 & -7099 & 563 & 4063 & -1069 & -004 \\
\hline $1 b$ & 002 & -7147 & 808 & 5089 & -809 & -053 \\
\hline $1 c$ & 144 & -7226 & 468 & 3808 & -1007 & 076 \\
\hline $1 e$ & 045 & -7287 & 615 & 4392 & -958 & 055 \\
\hline $1 f$ & 195 & -7387 & 430 & 5238 & -820 & 193 \\
\hline $1 \mathrm{~h}$ & -240 & -6529 & 782 & 6532 & -597 & -223 \\
\hline $1 \mathrm{k}$ & -073 & -6997 & 545 & 5536 & -743 & 015 \\
\hline 11 & 024 & -6955 & 419 & 4939 & -896 & 031 \\
\hline 10 & -119 & -6651 & 709 & 6251 & -859 & -162 \\
\hline $1 p$ & -210 & -6268 & 315 & 3493 & -1115 & -219 \\
\hline $2 \mathbf{a}$ & -121 & -7128 & 866 & 4448 & -1175 & -111 \\
\hline $2 e$ & -222 & -6688 & 838 & 5266 & -870 & -229 \\
\hline $3 \mathrm{e}$ & -142 & -6984 & 627 & 3646 & -1232 & -087 \\
\hline $3 f$ & 228 & -7524 & 430 & 4058 & -898 & 210 \\
\hline $4 b$ & 178 & -7682 & 542 & 3471 & -945 & 204 \\
\hline $4 e$ & -036 & -7111 & 601 & 3985 & -1167 & -019 \\
\hline
\end{tabular}

Table 12: Docked poses and their SF terms as selected by the $\mathrm{SF}_{8}$ Scoring Function Energy values in $\mathrm{kcal} / \mathrm{mol}$

The calculated log RBA values are very close to the experimental values, as can be seen by the excellent correlation in Figure 24 There are no outliers in the fit and the values are well spread across the range of log RBA values

The second half of Figure 24 shows that the top binding mode for E2 now contains 


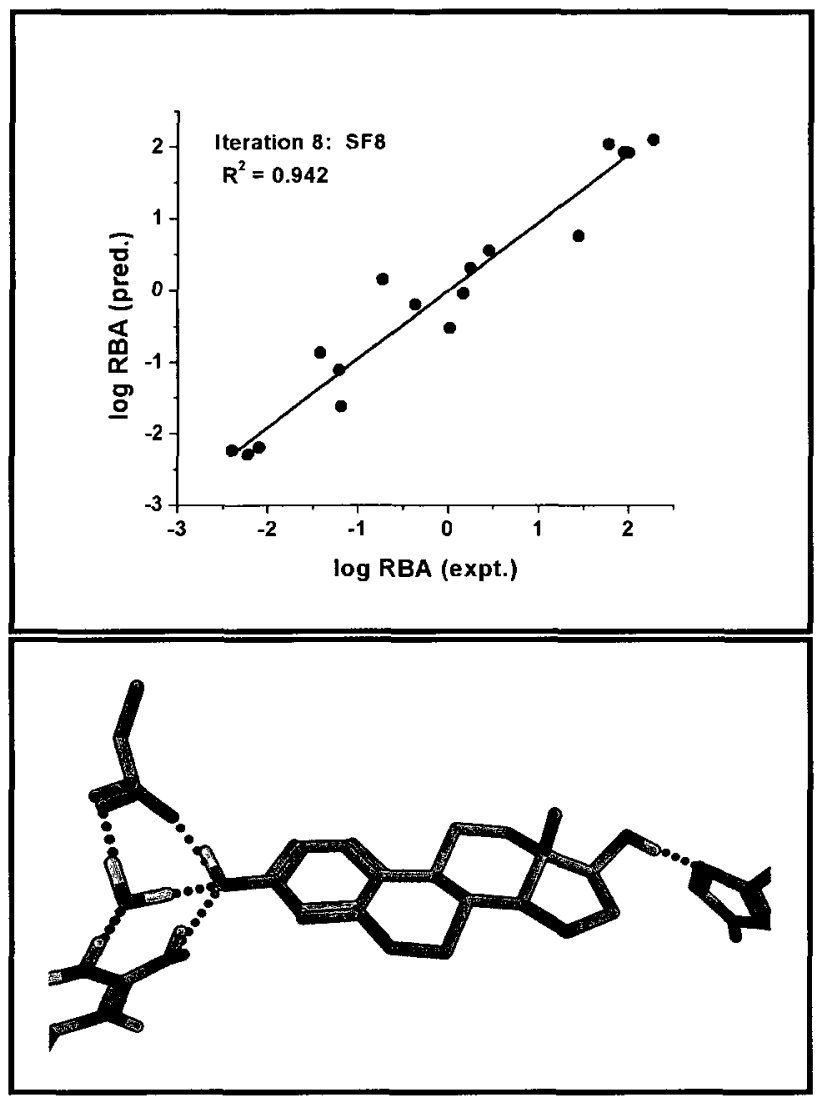

Figure 24: Correlation between the predicted $\log \mathrm{RBA}$ calculate using $\mathrm{SF}_{8}$ and the experimental $\log$ RBA values for Training Set 1 (left). Top-ranked binding mode of $\mathrm{E} 2$, as given by the top-ranked pose from $\mathrm{SF}_{8}$ (right).

all the features that are present in the crystal structure binding mode.

\subsubsection{Validation on Test Set 1}

Once the final iteratively optimized scoring function was obtained, the predicted log RBA values were calculated for the docked poses of Test Set 1 . The poses in Test Set 1 were re-ranked using $\mathrm{SF}_{8}$ and the top pose was selected for each ligand. These top poses were selected and the terms can be seen in Table 13, where it can be observed that the values of $\log \mathrm{RBA}$ (pred.) are reasonably close to those of the experimentally obtained $\log \mathrm{RBA}(\operatorname{expt}$.$) .$ 


\begin{tabular}{ccccccc}
\hline Ligand & $\log \mathbf{R B A}_{(e x p t)}$ & $\mathrm{E}_{\text {nnt }}$ & $\Delta \mathbf{E}_{L}$ & $\Delta \mathbf{E}_{R}$ & $\Delta \mathbf{G}_{\text {solv }}$ & $\log$ RBA (calc.) \\
\hline \hline $\mathbf{1 d}$ & 172 & -7419 & 503 & 4030 & -918 & 140 \\
$\mathbf{1 g}$ & 140 & -6660 & 499 & 5657 & -853 & -088 \\
$\mathbf{1 i}$ & 066 & 7381 & 727 & 5032 & -713 & 066 \\
$\mathbf{1 j}$ & -042 & -6950 & 636 & 4383 & -725 & 070 \\
$\mathbf{1 q}$ & -106 & -6843 & 481 & 5004 & -919 & -033 \\
$\mathbf{2 f}$ & 240 & 6649 & 1025 & 6716 & -686 & -277 \\
$\mathbf{3 a}$ & -061 & -7101 & 432 & 3011 & 1177 & 020 \\
$\mathbf{3 b}$ & 229 & -7173 & 351 & 4569 & -1019 & 125 \\
$\mathbf{4 a}$ & -038 & -6990 & 403 & 4648 & -1122 & 037 \\
$\mathbf{4 f}$ & 209 & -7754 & 462 & 4120 & 832 & 283
\end{tabular}

Table 13: Energy terms for poses of Test Set 1 as selected by $\mathrm{SF}_{8}$, the converged scoring function determined by Training Set 1 Energy values in $\mathrm{kcal} / \mathrm{mol}$

In addition to the small variation between $\log \mathrm{RBA}$ (pred) and $\log \mathrm{RBA}$ (expt), the individual terms are quite good as well For example, the values of $\mathrm{E}_{\text {ınt }}$ range from -66 to $-77 \mathrm{kcal} / \mathrm{mol}$ All the values of $\Delta \mathrm{E}_{L}$ are below $105 \mathrm{kcal} / \mathrm{mol}$ and all the $\Delta \mathrm{E}_{R}$ terms are less than $68 \mathrm{kcal} / \mathrm{mol}$

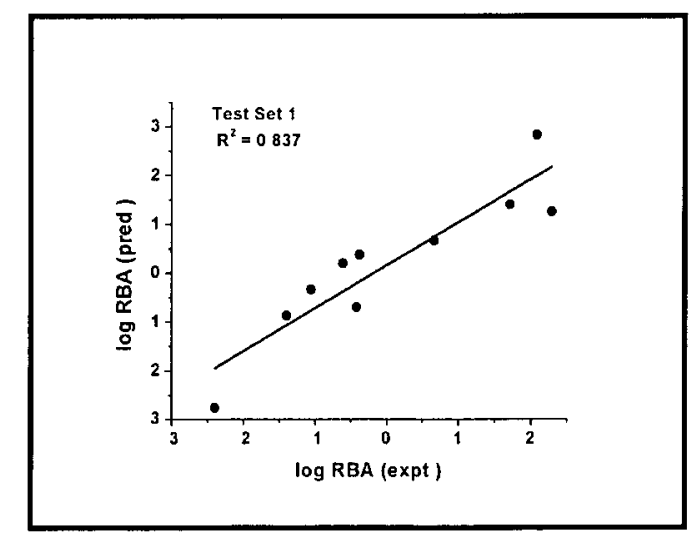

Figure 25: Calculated vs expermental log RBAs for Test Set 1, using coefficients from $\mathrm{SF}_{8}$

The correlation between experimental and calculated log RBA values for Test Set 1 (Figure 25), although weaker than that of the training set, still has a significant 
correlation coefficient $\mathrm{R}^{2}=0.837$. This indicates that the SF developed using Training Set 1 has predictive value even among ligands not used to calibrate the scoring function.

\subsubsection{Validation on Trans A-CD Compounds}

Another test for the scoring function is to see how well it predicts compounds that have different structures. The trans- data set contains compounds that have reasonably large differences in the main structure. Although the scoring function was not trained on these compounds, it will be tested on them to see if it can predict the binding affinity of trans- accurately. As with Test Set 1, the DPs were ranked using SF8 and the top pose of each was retained. The top poses for each compound are contained in Table 14 and produced a moderate correlation with the experimental log RBAs as shown in Figure 26.

\begin{tabular}{ccc}
\hline Ligand & $\log \mathrm{RBA}_{(\text {expt. })}$ & $\log \mathrm{RBA}$ (calc.) \\
\hline \hline 1b-t & 0.23 & -0.52 \\
1c-t & 0.62 & 0.91 \\
1e-t & -0.33 & 0.43 \\
1f-t & 0.68 & 0.83 \\
1i-t & -0.04 & 0.48 \\
4b-t & 0.99 & 1.57 \\
4c-t & 1.34 & 1.2
\end{tabular}

Table 14: Predicted binding affinites for top poses of the trans- A-CD set as selected by SF8. 


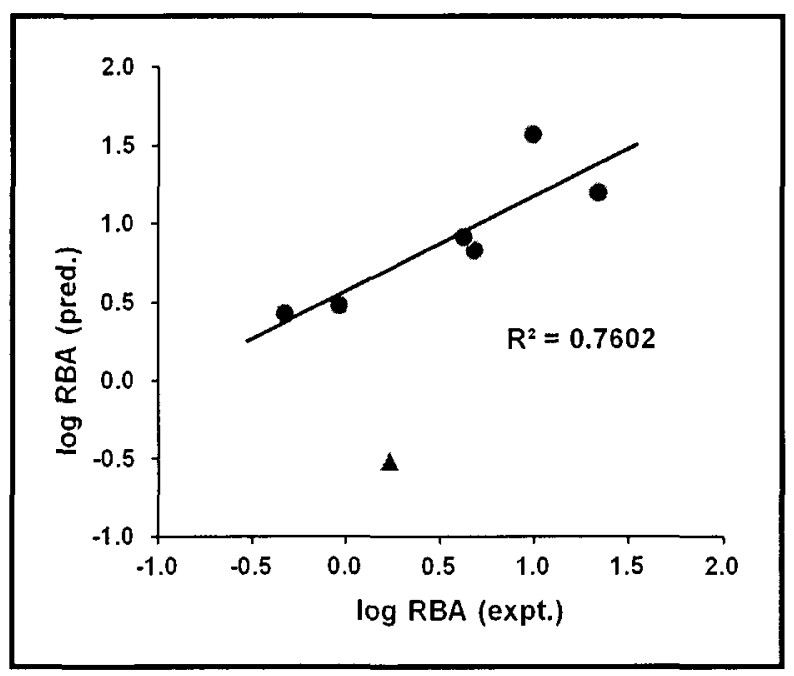

Figure 26: Calculated vs. experimental log RBAs for trans-A-CD set, using coefficients from $\mathrm{SF}_{8}$.

Although the correlation was rather poor, with $R^{2}=0.45$, elimination of one outlier increased the correlation to $\mathrm{R}^{2}=0.76$. The data range is only just under $2 \mathrm{kcal} / \mathrm{mol}$ which is rather low. Compared to the cus- training and test sets with data ranges of $4-5 \mathrm{kcal} / \mathrm{mol}$ this is a poor data spread. There are possibly two factors that account for the worse prediction of trans-vs cis-compounds. First, the trans-compounds may bind in significantly different ways than the cas-compounds. If this were the case, it would be unreasonable to assume that a SF trained on $c \imath s-\mathrm{A}-\mathrm{CD}$ compounds would be predictive of this new binding mode. The second possibility is that the data spread is so small that it is difficult to producc a good correlation. Improving the spread by including more experimental data might increase the correlation to make it comparable to that of Test Set 1. Unfortunately, the only way to test this hypothesis is to synthesize more compounds to fill out the set. 


\subsubsection{Validation Against Overfitting}

There is a danger of overfitting when using iterative methods to fit experimental data. This has been mentioned by several authors, including Martin et al. [45, Martin and Sullivan 2008] and various sources referenced within. Thus, before much confidence can be put in the procedure, there should be several validation tests performed to characterize the potential downfalls of this method. One possibility is that this iterative process is fitting noise and, thus, producing a correlation which appears unrealistically good. Another possibility is that the specific training set chosen randomly happened to give a fit that worked for the test set as well.

The first possibility will be examined by randomly scrambling the experimental RBA data and performing the iterative optimization over this new data set. The scrambling was accomplished by swapping values of each ligand randomly with that of another. This method was chosen rather than assigning completely new RBA values as it gave an identical range and distribution of RBA values in the end. To test the second possibility several different training sets were generated, along with their respective test sets. This will allow us to determine if it was random chance that the chosen training set produced a fit that also gave acceptable predictions for the test set. If the iterative method works, it will be expected that there will be a certain similarity between each fitted equation generated by each test set.

\section{Scrambled RBAs}

The first test for this method was the scrambling of experimental RBAs to observe the extent of noise fitting. The resulting training set was completely uncorrelated to the initial RBA values, as shown in Figure 27.

The same iterative procedure was carried out for this scrambled set as for the previous training sets. It can be seen that the iterative procedure did not produce 


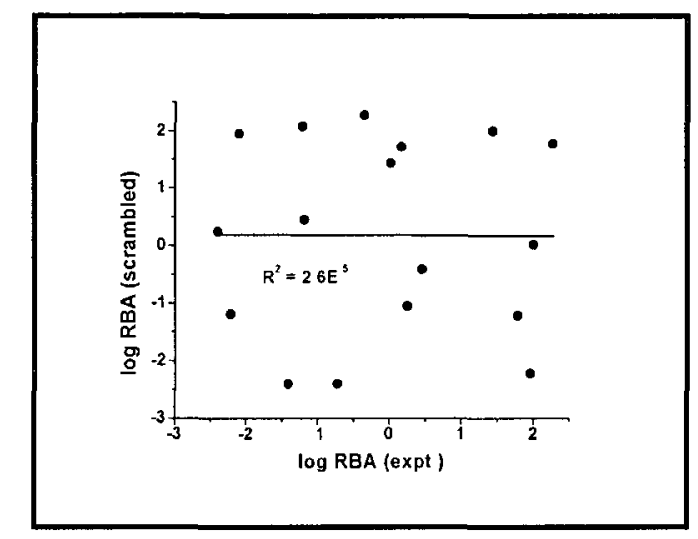

Figure 27: Correlation between scrambled log RBAs and experimental log RBAs, without a significant fit.

the same smooth convergence as in the previous examples. Instead, there were wild oscillations in the correlation coefficient over the first iterations, ending with a final cyclic convergence after about 30 iterations (Figure 28). The final correlation coefficient cycled at values with $\mathrm{R}^{2}<0.2$.

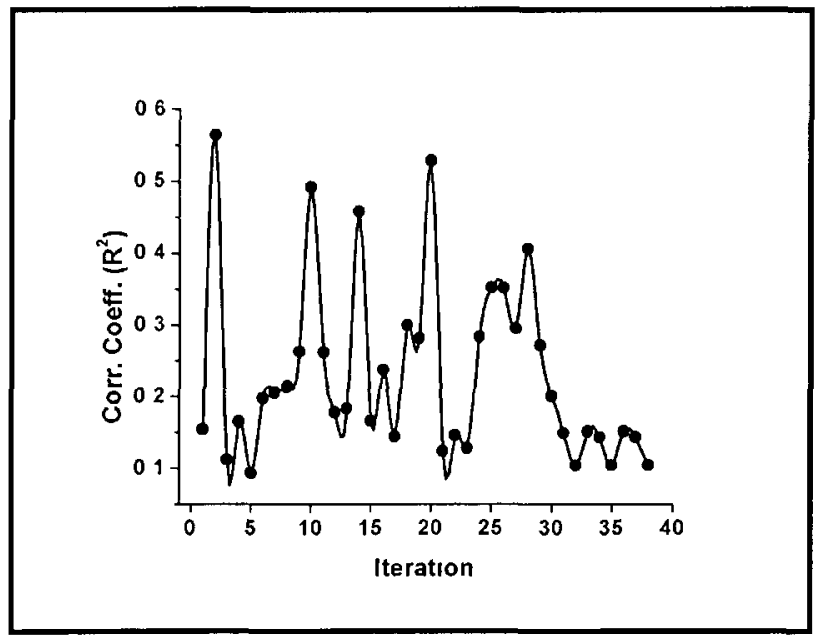

Figure 28: Value of the correlation coefficient $\left(\mathrm{R}^{2}\right)$ as a function of iteration number for the scrambled training set.

The poor quality of the correlations and the lack of smooth convergence show that the iterative scoring function treats random noise differently than it does meaningful 
data. When given data with no correlation to the real binding affinities, the iterative scoring function fails to produce a significant correlation.

\section{Additional Training and Test Sets}

Three additional training sets, 2, 3 and 4, were generated using the same selection criteria as for Training Set 1. Each set contained 17 ligands with compounds from series 1, 2, 3 and 4 and with RBA values spread across low, medium and high RBA values. Due to the fact that it is our reference compound, E2 was also included in each training set. As can be seen in Figure 29, each training set converged in around 5-7 iterations. In each case, the correlation coefficient also converged around $\mathrm{R}^{2}=$ 0.9 or better.
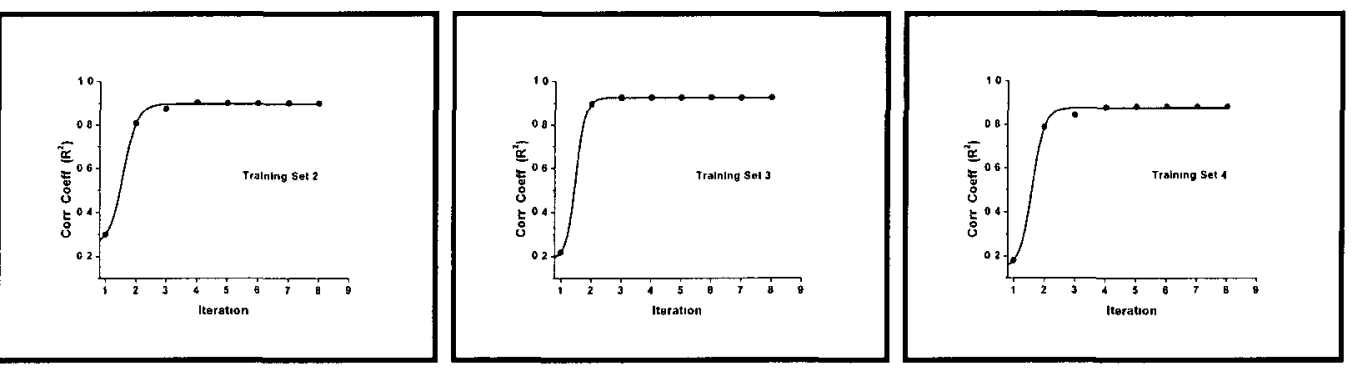

Figure 29: Convergence properties for the additional training sets, showing the change of correlation coefficient $\mathrm{R}^{2}$ over iteration. (left) Training Set 2, (middle) Training Set 3, (right) Training Set 4.

The coefficient values for the first and last iterations of Training Sets 1, 2, 3 and 4 as well as the number of iterations required to reach convergence are contained in Table 15. The correlation obtained for the test sets as well as their composition are also contained in the table. 


\begin{tabular}{|c|c|c|c|}
\hline Training Set & Initial $\mathbf{R}^{2}$ & Final $\mathbf{R}^{2}$ & Number of iterations \\
\hline 1 & 0245 & 0942 & 8 \\
\hline 2 & 0300 & 0900 & 6 \\
\hline 3 & 0219 & 0925 & 3 \\
\hline 4 & 0181 & 0883 & 6 \\
\hline Test Set & Composition & $\mathbf{R}^{2}$ & \\
\hline 1 & $1 \mathrm{~d}, 1 \mathrm{~g}, 1 \mathrm{l}, 1 \mathrm{~J}, 1 \mathrm{q}, 2 \mathrm{f}, 3 \mathrm{a}, 3 \mathrm{~b}, 4 \mathrm{a}, 4 \mathrm{f}$ & 0834 & none \\
\hline 2 & $1 \mathrm{c}, 1 \mathrm{f}, 1 \mathrm{~h}, 1 \mathrm{l}, 1 \mathrm{o}, 2 \mathrm{a}, 3 \mathrm{e}, 3 \mathrm{f}, 4 \mathrm{~b}, 4 \mathrm{e}$ & 0786 & none \\
\hline 3 & $1 \mathrm{~b}, 1 \mathrm{e}, 1 \mathrm{f}, 1 \mathrm{l}, 1 \circ 2 \mathrm{e}, 3 \mathrm{~b}, 3 \mathrm{e}, 4 \mathrm{a}, 4 \mathrm{~b}$ & 0859 & none \\
\hline 4 & $1 \mathrm{~b}, 1 \mathrm{c}, 1 \mathrm{f}, 1 \mathrm{~h}, 1 \mathrm{p}, 2 \mathrm{a}, 3 \mathrm{a}, 3 \mathrm{f}, 4 \mathrm{e}, 4 \mathrm{f}$ & 0927 & none \\
\hline
\end{tabular}

Table 15: Properties of the Tramıng and Test Sets 2, 3 and 4 are shown Data for Set 1 are included for comparison

The four training sets all converge with good consistency, with final $R^{2}$ values in the range of $091 \pm 003$ The convergence indicates that the scoring functıons are focusing in on the best pose for each ligand Each of the test sets also produced significant correlations, with the $\mathrm{R}^{2}=085 \pm 01$ This test has demonstrated that not only is the iterative procedure robust in its ability to obtain simılar results regardless of exact training and test sets, but it is also capable of producing fits with significant predictive power $\left(R^{2}>078\right.$ for test sets) 


\section{Chapter 4}

\section{Conclusion}

\subsection{Part I. Substituent Effects}

The $\mathrm{BDE}_{\mathrm{OH}}$ for unsubstituted phenol was calculated to be $87.48 \mathrm{kcal} / \mathrm{mol}$, which agrees well with the experimental value of $87.2 \pm 0.1 \mathrm{kcal} / \mathrm{mol}$.

Comparison to available literature BDE values shows that the calculated monohalogenated $\triangle B D E$ s fit within the uncertainties of the experimental values and correlate with a coefficient $R^{2}=0.73$.

The halogens also show the expected change from EWG effects in the meta position to EDG effects in either the ortho or para positions.

The training produced correlation coefficients $\mathrm{R}^{2}>0.99$ and the following equations:

$$
\begin{aligned}
& \triangle B D E=2.74 * \#_{H-b o n d s}-1.68 * \#_{\text {ortho-F }}+1.02 * \#_{\text {meta }-F}-2.02 * \#_{\text {para }-F} \\
& \triangle B D E=3.19 * \#_{H-\text { bonds }}-1.42 * \#_{\text {ortho }-C l}+1.02 * \#_{\text {meta }-C l}-1.39 * \#_{\text {para }-C l} \\
& \triangle B D E=3.25 * \#_{H-\text { bonds }}-1.35 * \#_{\text {ortho- } B r}+0.97 * \#_{\text {meta }-B r}-1.04 * \#_{\text {para }-B r}
\end{aligned}
$$

The substituent constants obtained were found to predict $\mathrm{BDE}_{O H}$ values accurately for a mixed polyhalogenated test set, producing an overall correlation coefficient of $\mathrm{R}^{2}=0.97$ and demonstrating the additivity of the derived constants.

This work has shown that a simple MLR fit on calculated $\triangle \mathrm{BDE}_{O H}$ values can 
produce substituent constants for ortho-, meta- and para- halogenated compounds. These constants can be used like Hammett parameters to accurately predict $\triangle \mathrm{BDE}$ values for arbitrarily substituted compounds. This has potential use in the development of anti-oxidants as these can be used to quickly and easily predict the $\mathrm{BDE}_{\mathrm{OH}}$ of a suggested compound before synthesis begins.

This work could be improved by calculating parameters for a variety of substituents that are commonly used. This would allow prediction of $\triangle \mathrm{BDE}_{O H}$ values for a greater number of compounds and increase the applicability of these constants. Further work in this area would involve designing promising compounds based on these constants, developing and testing them.

\subsection{Part II. Iterative Scoring Functions}

The iterative procedure for Training Set 1 converged smoothly and achieved and excellent correlation coefficient of $\mathrm{R}^{2}=0.942$ with std. dev. $=0.365 \log$ unit.

The final optimized scoring function is:

$\mathrm{SF}_{8}\left(\log \mathrm{RBA}_{\text {pred. }}\right)=-24.23-0.362 * \mathrm{E}_{\text {znt }}-0.413^{*} \Delta \mathrm{E}_{L}+0.0266^{*} \Delta \mathrm{E}_{R}+0.0268^{*} \Delta \mathrm{G}_{\text {solv }}$.

This scoring function was tested on Test Set 1 and produced a correlation coefficient of $\mathrm{R}^{2}=0.837$ which shows that the scoring function has predictive value among similar compounds not contained in the training set.

A small set of trans A-CD compounds were also predicted using SF8 and produced a correlation coefficient of $R^{2}=0.45\left(R^{2}=0.76\right.$ with one outlier $)$, which was not ideal. However, the data spread was quite low for this test set and so it is hypothesized that increasing the number of data points would improve the correlation.

A test was performed to check against overfitting of the data. First, the experimental data was scrambled and the iterative procedure was performed. This optimization lacked the smooth convergence of the previous training set and produced a 
poor correlation of $\mathrm{R}^{2}<0.2$. This showed that the optimization was not overfitting scrambled data in the same way as it was real binding affinities.

Three additional training and test sets were produced to see if similar results could be obtained with different combinations of training and test compounds. In each case smooth convergence was observed resulting in excellent predictive abilities. Correlations coefficients had a range of $\mathrm{R}^{2}=0.91 \pm 0.03$ for the training set and $\mathrm{R}^{2}$ $=0.85 \pm 0.1$ for the test set.

These tests have demonstrated that the iterative procedure is capable of iteratively optimizing a scoring function by optimizing the selection of docked poses until convergence is achieved. The results were excellent for cis A-CD compounds and it appears that more data may improve the fit for trans A-CD compounds.

A future direction for furthering this work would be to increase the experimental data on the trans A-CD series to better test the power of the scoring function. Using this procedure to optimize scoring functions for other receptors, such as ER $\beta$ or the androgen receptor would demonstrate the generality of this method. In future, this method could be used to test compounds not already synthesized and produce insight into promising candidates. 


\section{List of References}

[1] J S Wright, D. J. Carpenter, D. J. McKay, and K. U. Ingold. Journal of the Amerıcan Chemucal Socıety 119(18), 4245-4252 (1997).

[2] D. Colton, Carol; Gilbert. Reactıve Oxygen Specıes in Brologıcal Systems. Kluwer Academic Publishers (2002).

[3] S. J Klebanoff. Scrence 169(3950), 1095-1097 (1970).

[4] B. Halliwell, G. J.M., and C. Cross. Journal of Laboratory and Clınıcal Medıcıne 119(6), 598-620 (1992).

[5] E. Klein and V. Lukes. Chemıcal Physıcs 330(3), 515 - 525 (2006).

[6] Z. Rappoport. The Chemıstry of Phenols PATAI'S Chemistry of Functional Groups. John Wiley \& Sons. ISBN 9780470869451 (2004).

[7] G. W. Burton and M. G. Traber. Annual Review of Nutrition 10(1), 357-382 (1990).

[8] L. Frmont, L. Belguendouz, and S. Delpal. Life Scrences 64(26), 2511 - 2521 (1999).

[9] I. Bjorkhem, A. Henriksson-Freyschuss, O. Breuer, U. Diczfalusy, L. Berglund, and P. Henriksson. Arteriosclerosis, Thrombosis, and Vascular Bıology 11(1), $15-22$ (1991).

[10] A. Branen. Journal of the American Oul Chemists' Society 52, 59-63. 10.1007/BF02901825 (1975).

[11] E. T. Denisov and I. V. Khudyakov. Chemıcal Reviews 87(6), 1313-1357 (1987).

[12] B. Halliwell and J. Gutteridge. Free radıcals in brology and medıcıne. Clarendon Press. ISBN 9780198552949 (1989). 
[13] Q. Zhu, X.-M. Zhang, and A J. Fry. Polymer Degradation and Stabılıty 57(1), $43-50$ (1997).

[14] A. K. Chandra and T. Uchimaru. International Journal of Molecular Sciences 3(4), 407-422 (2002).

[15] M. G. D. Nix, A. L. Devine, B. Cronin, R. N. Dixon, and M. N. R. Ashfold. Phys. Chem Chem. Phys. 125(13), 133318 (13 pages) (2006).

[16] H.-Y. Zhang, Y.-M. Sun, and D.-Z. Chen. Quantrtatıve Structure-Actrvity Relationships 20(2), 148-152 (2001).

[17] R. M. B. dos Santos and J. A. M. Simes 27(3), 707-739 (1998).

[18] C. Hansch, A. Leo, and R W. Taft. Chemıcal Revıews 91(2), 165-195 (1991).

[19] H. C. Brown, Y. Okamoto, and G Ham. Journal of the American Chemical Socrety 79(8), 1906-1909 (1957).

[20] P. Mulder, H.-G. Korth, D. A. Pratt, G. A. DiLabio, L. Valgimigli, G. F. Pedulli, and K. U. Ingold. The Journal of Physical Chemistry A 109(11), 2647-2655 (2005).

[21] L. Wang and A. Tang. International Journal of Chemical Krnetıcs 43(2), 62-69 (2011).

[22] J. Shorter. ChemInform 31(33), no-no (2000).

[23] T. Brinck, M. Haeberlein, and M. Jonsson. Journal of the American Chemical Socrety 119(18), 4239-4244 (1997).

[24] D. J. V. A. dos Santos, A. S. Newton, R. Bernardino, and R. C. Guedes. International Journal of Quantum Chemustry 108(4), 754-761 (2008).

[25] A. R. Leach Molecular modellng. principles and applıcatıons. Pearson Education. Prentice Hall. ISBN 9780582382107 (2001).

[26] A. D. Becke. Journal of Chemıcal Physıcs 98(7), 5648-5652 (1993).

[27] C. Lee, W. Yang, and R. G. Parr. Phys. Rev. B 37, 785-789 (1988).

[28] K. Dahlman-Wright, V. Cavailles, S. A. Fuqua, V. C. Jordan, J. A. Katzenellenbogen, K. S. Korach, A. Maggi, M. Muramatsu, M. G. Parker, and J.-k Gustafsson. Pharmacologıcal Revıews 58(4), 773-781 (2006). 
[29] J. I. Macgregor and V. C. Jordan. Pharmacological Reveews 50(2), 151196 (1998).

[30] J S. Wright, H. Shadnia, J. M. Anderson, T. Durst, M. Asim, M. El-Salfiti, C. Choueiri, M. A. C. Pratt, S. C. Ruddy, R. Lau, K. E. Carlson, J. A. Katzenellenbogen, P. J. OBrien, and L. Wan. Journal of Medıcınal Chemıstry 54(2), 433-448 (2011).

[31] M. Asim, M. El-Salfiti, Y. Qian, C. Choueiri, S. Salari, J Cheng, H. Shadnia. M. Bal, M. C. Pratt, K. E. Carlson, J. A. Katzenellenbogen, J. S. Wright, and T. Durst. Bioorganıc \& \&edicinal Chemistry Letters 19(4), 1250 - 1253 (2009).

[32] T. A. Halgren. Journal of Computational Chemıstry 17(5-6), 490-519 (1996).

[33] I. D. Kuntz, J. M. Blaney, S. J. Oatley, R. Langridge, and T. E. Ferrin. Journal of Molecular Bıology 161(2), 269 - 288 (1982).

[34] N. Moitessier, P. Englebienne, D. Lee, J. Lawandi, and C. R. Corbeil. Brıtısh Journal of Pharmacology 153(S1), S7-S26 (2008).

[35] G. L. Warren, C. W. Andrews, A.-M. Capelli, B. Clarke, J LaLonde, M. H. Lambert, M. Lindvall, N. Nevins, S. F. Semus, S. Senger, G. Tedesco, I. D. Wall, J. M. Woolven, C. E. Peishoff, and M. S. Head. Journal of Medicinal Chemıstry 49(20), 5912-5931 (2006).

[36] W. L. Jorgensen and J. Tirado-Rives. Journal of the Amerzcan Chemıcal Socıety 110(6), 1657-1666 (1988).

[37] S. Dapprich, I. Komromi, K. S. Byun, K. Morokuma, and M. J. Frisch. Journal of Molecular Structure: THEOCHEM 461-462, 1 - 21 (1999).

[38] K. Raha and K. M. Merz. Journal of Medıcınal Chemıstry 48(14), 4558-4575 (2005).

[39] K. M. Merz. Journal of Chemıcal Theory and Computatıon 6(5), 1769-1776 (2010).

[40] S.-Y. Huang and X. Zou. Proteins: Structure, Function, and Bionnformatics 66(2), 399-421 (2007).

[41] E. Stjernschantz and C. Oostenbrink. Brophysıcal Journal 98(11), 2682 - 2691 (2010). 
[42] H. F. G. Velec, H. Gohlke, and G. Klebe. Journal of Medıcınal Chemıstry 48(20), 6296-6303 (2005).

[43] D. Hecht and G. B. Fogel. Current Computer - Azded Drug Design 5(1), 56-68 (2009).

[44] S.-Y. Huang and X. Zou. Journal of Computational Chemistry 27(15), 18661875 (2006).

[45] E. J. Martin and D. C. Sullivan. Journal of Chemical Information and Modeling $48(4), 861-872(2008)$.

[46] M. J. Frisch, G. W. Trucks, H. B. Schlegel, G. E. Scuseria, M. A. Robb, J. R. Cheeseman, G. Scalmani, V. Barone, B. Mennucci, G. A. Petersson, H. Nakatsuji, M. Caricato, X. Li, H. P. Hratchian, A. F. Izmaylov, J. Bloino, G. Zheng, J. L. Sonnenberg, M. Hada, M. Ehara, K. Toyota, R. Fukuda, J. Hasegawa, M. Ishida, T. Nakajima, Y. Honda, O. Kitao, H. Nakai, T. Vreven, J. A. Montgomery, Jr., J. E. Peralta, F. Ogliaro, M. Bearpark, J. J. Heyd, E. Brothers, K. N. Kudin, V. N. Staroverov, R. Kobayashi, J. Normand, K. Raghavachari, A. Rendell, J. C. Burant, S. S. Iyengar, J. Tomasi, M. Cossi, N. Rega, J. M. Millam, M. Klene, J. E. Knox, J. B. Cross, V. Bakken, C. Adamo, J. Jaramillo, R. Gomperts, R. E. Stratmann, O. Yazyev, A. J. Austin, R. Cammi, C. Pomelli, J. W. Ochterski, R. L. Martin, K. Morokuma, V. G. Zakrzewski, G. A. Voth, P. Salvador, J. J. Dannenberg, S. Dapprich, A. D. Daniels, . Farkas, J. B. Foresman, J. V. Ortiz, J. Cioslowski, and D. J. Fox. "Gaussian 09 Revision A.1." Gaussian Inc. Wallingford CT 2009.

[47] "Molecular operating environment (moe), version 2009.10." Chemical Computing Group Inc.: Montreal, Quebec, Canada, 2009.

[48] G. A. Dilabio, D. A. Pratt, A. D. Lofaro, and J. S. Wright. The Journal of Physıcal Chemıstry A 103(11), 1653-1661 (1999).

[49] http://www.gaussian.com/g_tech/g_ur/k_dft.htm. "Gaussian user reference."

[50] E. R. Johnson, O. J. Clarkin, and G. A. DiLabio. The Journal of Physical Chemistry A 107(46), 9953-9963 (2003).

[51] T. A. Halgren. Journal of Computational Chemistry 20(7), 720-729 (1999).

[52] www.rcsb.org. "Rcsb." 
[53] A. Warnmark, E. Treuter, J.-k. Gustafsson, R. E. Hubbard, A. M. Brzozowski, and A. C. W. Pike. Journal of Bıological Chemıstry 277(24), 21862-21868 (2002).

[54] P. Prathipati and A. K. Saxena. Journal of Chemıcal Information and Modeling $46(1), 39-51$ (2006).

[55] M. De Angelis, F. Stossi, K. A. Carlson, B. S. Katzenellenbogen, and J. A. Katzenellenbogen. Journal of Medıcınal Chemıstry 48(4), 1132-1144 (2005)

[56] P. A. Kollman and L. C. Allen. Journal of Chemıcal Physıcs 52(10), 5085-5094 (1970).

[57] A. W. Baker and W. W. Kaeding. Journal of the American Chemical Society 81(22), 5904-5907 (1959).

[58] G P. Bean. Tetrahedron 58(50), 9941 - 9948 (2002).

[59] M. Charton. Canadaan Journal of Chemustry 38(12), 2493-2499 (1960).

[60] C. G. Swain and E. C. Lupton. Journal of the Amerıcan Chemical Socrety 90(16), 4328-4337 (1968). 


\section{Appendix A}

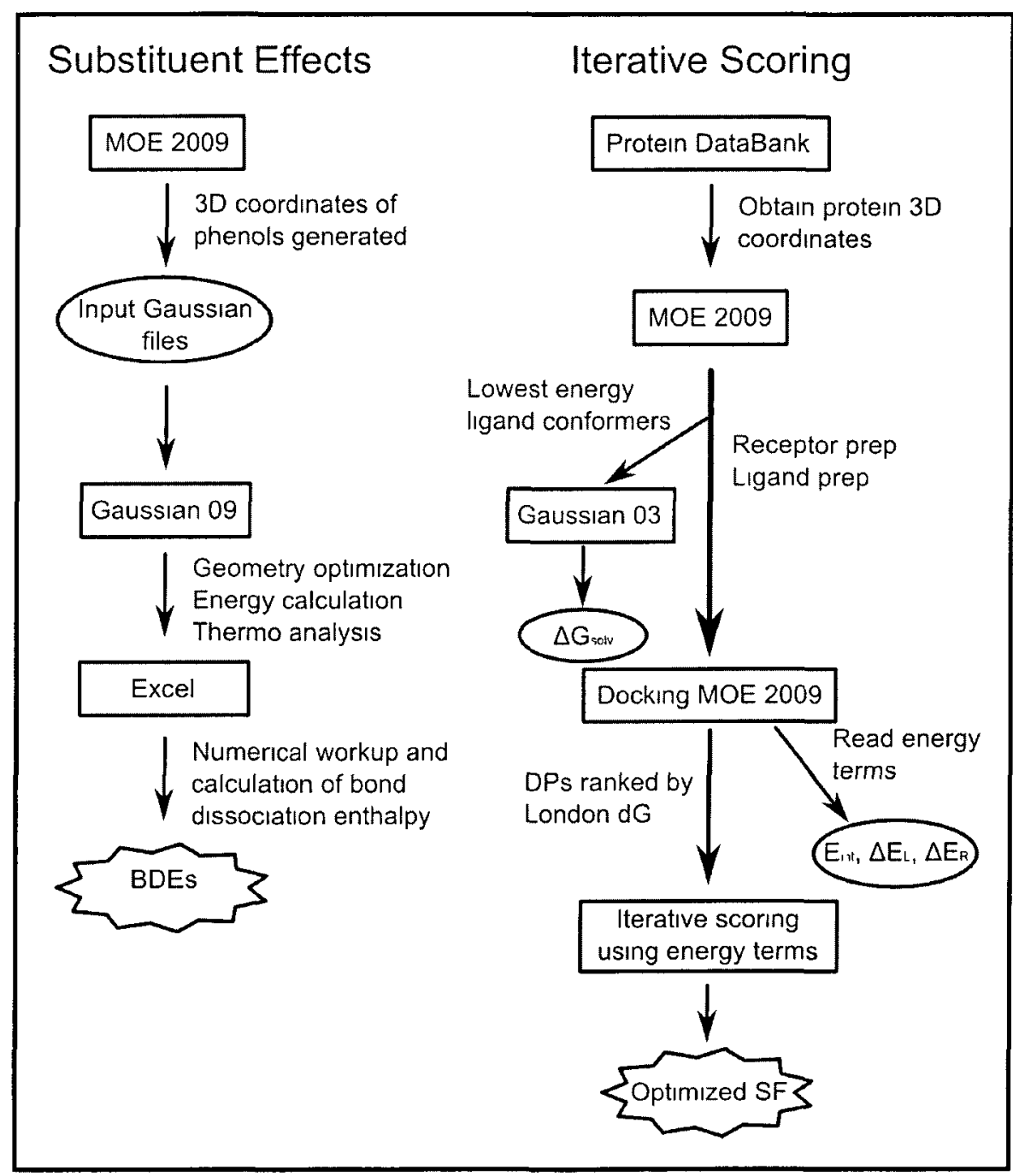

Figure 30: A flow chart showing the varıous steps involved in the calculations 